\title{
Metabolic Syndrome and Cardiovascular Disease Impacts on the Pathophysiology and Phenotype of HIV-Associated Neurocognitive Disorders
}

\author{
Antoine Moulignier and Dominique Costagliola
}

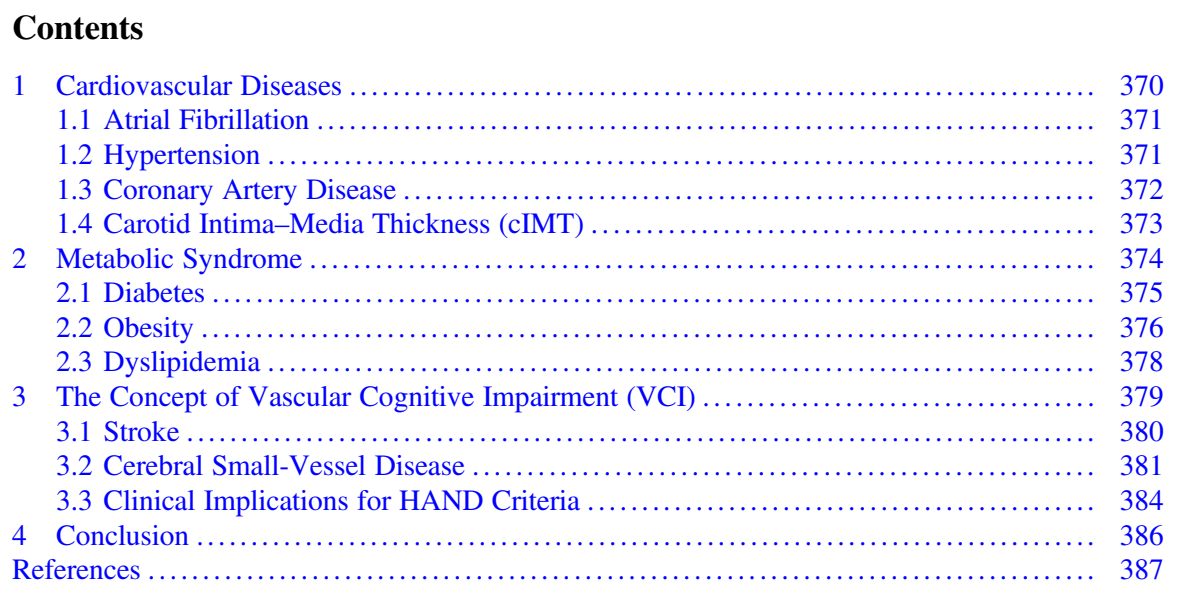

\begin{abstract}
Evidence from epidemiological studies on the general population suggests that midlife cardiovascular disease (CVD) and/or metabolic syndrome (MetS) are associated with an increased risk of cognitive impairment and dementia later in life. In the modern combined antiretroviral therapy (cART) era, as in the general population, CVD and MetS were strongly and independently associated with poorer cognitive performances of sustained immunovirologically controlled persons living with human immunodeficiency viruses (PLHIVs). Those findings suggest that $\mathrm{CV} /$ metabolic comorbidities could be implicated in the pathogenesis of HIV-associated neurocognitive disorders (HAND) and might be more important
\end{abstract}

\footnotetext{
A. Moulignier $(\triangle)$

Department of Neurology, Memory Clinic, Fondation Adolphe de Rothschild, Paris, France e-mail: amoulignier@for.paris

D. Costagliola $(\bowtie)$

INSERM, Sorbonne Université, Institut Pierre-Louis d'Epidémiologie et de Santé Publique (IPLESP), Paris, France

e-mail: dominique.costagliola@iplesp.upmc.fr
} 
than factors related to HIV infection or its treatment, markers of immunocompetence, or virus replication. The association between CVD/MetS and cognition decline is driven by still not well-understood mechanisms, but risk might well be the consequence of increased brain inflammation and vascular changes, notably cerebral small-vessel disease. In this review, we highlight the correspondences observed between the findings concerning CVD and MetS in the general population and virus-suppressed cART-treated PLHIVs to evaluate the real brain-aging processes. Indeed, incomplete HIV control mainly reflects HIV-induced brain damage described during the first decades of the pandemic. Given the growing support that CVD and MetS are associated with HAND, it is crucial to improve early detection and assure appropriate management of these conditions.

Keywords Adiposity · AIDS · Atrial fibrillation · Body mass index · Cardiovascular diseases · Cardiovascular risk factors · Carotid intima-media thickness · Cerebral small-vessel disease $\cdot$ Cognitive impairment $\cdot$ Coronary artery disease $\cdot$ Diabetes · Dyslipidemia $\cdot$ HIV, human immunodeficiency virus $\cdot$ HIV-associated neurocognitive disorders (HAND) · Hypertension · LDL cholesterol · Metabolic syndrome $\cdot$ Obesity $\cdot$ Stroke $\cdot$ Vascular cognitive impairment $(\mathrm{VCI}) \cdot$ White-matter hyperintensities

\section{Abbreviations}

$\begin{array}{ll}\text { AF } & \text { Atrial fibrillation } \\ \text { AIDS } & \text { Acquired immunodeficiency syndrome } \\ \text { BBB } & \text { Blood-brain barrier } \\ \text { BMI } & \text { Body mass index } \\ \text { BP } & \text { Blood pressure systolic (SBP) and diastolic (DBP) } \\ \text { CAD } & \text { Coronary artery disease } \\ \text { cART } & \text { Combined antiretroviral therapy } \\ \text { cIMT } & \text { Carotid intima-media thickness } \\ \text { CSF } & \text { Cerebrospinal fluid } \\ \text { CSVD } & \text { Cerebral small-vessel disease } \\ \text { CV } & \text { Cardiovascular } \\ \text { CVD } & \text { CV disease } \\ \text { HAND } & \text { HIV-associated neurocognitive disorders } \\ \text { HCV } & \text { Hepatitis C virus } \\ \text { HDL-C } & \text { High-density lipoprotein cholesterol } \\ \text { HIV } & \text { Human immunodeficiency virus } \\ \text { LDL-C } & \text { Low-density lipoprotein cholesterol } \\ \text { MetS } & \text { Metabolic syndrome } \\ \text { MRI } & \text { Magnetic resonance imaging } \\ \text { plVL } & \text { Plasma HIV load } \\ \text { PLHIV } & \text { Person living with HIV } \\ \text { VCI } & \text { Vascular cognitive impairment } \\ \text { WMH } & \text { White-matter hyperintensity }\end{array}$


Combined antiretroviral therapy (cART) has made it possible for persons living with human immunodeficiency viruses (PLHIVs) to reach advanced age, and half of patients in high-income countries are now 50 years old or older (Costagliola 2014). Nevertheless, aging PLHIVs' life expectancy persistently lags behind that of the general population, predominantly because of their heightened risk for age-related comorbidities, to which they might be more vulnerable (Cohen et al. 2015; Wang et al. 2015). Among those age-related comorbidities, cardiovascular disease (CVD) and risk factors (i.e., hypertension, diabetes, obesity, dyslipidemia, atherosclerosis, and coronary artery disease (CAD)) are highly prevalent (Calò et al. 2013; Lang et al. 2015; Boccara and Cohen 2016). The pathophysiology underlying CVD and the metabolic syndrome (MetS) in this population is complex and involves traditional risk factors, and infection-relateds and ART-related parameters. Mounting evidence obtained from virus-suppressed cART-treated adult PLHIVs has underscored that CVD and MetS count more than conventional HIV-related factors for persistent HIV-associated neurocognitive disorders (HAND) (Bonnet et al. 2013; Wright et al. 2010; Fabbiani et al. 2013).

Indeed, as in the general population, CVD and MetS were strongly and independently associated with poorer cognitive performance in aviremic PLHIVs, suggesting that $\mathrm{CV} /$ metabolic comorbidities could play relevant role(s) in HAND pathogenesis in the modern cART era (Foley et al. 2010; Nakamoto et al. 2012). The hypothesis that HIV-attributable brain injury would occur mainly during untreated/ uncontrolled infection, and may reflect a combination of historical effects of HIV itself and immunosuppression, as well as the burden of systemic factors, e.g., CVD/MetS, lifestyle factors, and ongoing neuroinflammation, is more and more accepted (Sanford et al. 2019; van Zoest et al. 2018; Makinson et al. 2019). Indeed, most of today's aging PLHIVs are survivors of the pre-cART era, with long durations of HIV infection, more profound past immunodepression, less effective ART, and less strict plasma HIV-RNA control available at that time. All those factors affected epidemiological studies in older PLHIVs due to the immortal bias. Early cART initiation and full viral suppression may preserve long-term brain health for more recently diagnosed and successfully treated PLHIVs. Hence, the inflammation, encephalitis, and neurodegeneration that had been the forces driving brain pathophysiology before the advent of cART might no longer seem to fit the situation seen in successfully cART-treated PLHIVs. CV/metabolic changes - potentially reversible and primarily targeting the neurovascular unit - are now seen as one of the main drivers of HAND clinical-neuropathological manifestations (Gelman 2015). Thus, incomplete virus control mainly reflects HIV-induced brain damage described during the first decades of the pandemic (Sanford et al. 2019; Fleming et al. 2019). In addition to traditional vascular risk factors, current low CD4+ T-cell count and its nadir, viral detectability, and some previous ART were independently and strongly associated with increased CVD risk (Gutierrez et al. 2017). Unfortunately, although newer ART seemed significantly less metabolically toxic than early ART, integrasestrand-transfer inhibitors have a significant deleterious effect on body weight, body mass index (BMI), and glucose metabolism (Kerchberger et al. 2019; Lagathu et al. 2019; Hill et al. 2019). 
Management of PLHIVs' traditional CVD risk factors is suboptimal in primary and secondary preventive settings (Hatleberg et al. 2017). In the AGEhIV cohort, blood pressure (BP) and cholesterol levels were above target levels for 42 and $57 \%$ of PLHIVs eligible for secondary prevention (Hatleberg et al. 2017). Because cognitive functions seem to be more severely impacted and widespread by CVD and/or MetS effects when their control is insufficient, it has become extremely important to diagnose them, so as to initiate lifestyle changes and to potentially retard those risk factors' influence on cognitive decline in the modern cART era (Akbaraly et al. 2018; Barberger-Gateau et al. 2007). The 2019 UNAIDS world epidemiological data show that $79 \%$ of PLHIVs are aware of their seropositivity, $78 \%$ of PLHIVs knowing their HIV status are cART-treated, and $86 \%$ of those cART-treated PLHIVs have a plasma HIV load (plVL) below the detection threshold (unaids.org). Moreover, it was recently demonstrated that low plVL of 51-200 and 201-500 copies/mL were strongly associated with virological failure (Fleming et al. 2019). Those findings provide support for the European definition of virological failure as persistent plVL of $>50$ copies/mL (eacsociety.org). Hence, reporting results concerning virologically uncontrolled cART-treated PLHIVs is not really suitable. According to those worldwide results, including for low-income countries, in this review, we draw parallels between CVD and MetS findings based on numerous published studies conducted on the general population and those in cART-treated PLHIVs with sustained immunovirological control to evaluate the real brain-aging processes.

\section{Cardiovascular Diseases}

The absolute CVD risk increases with aging, and a growing body of evidence is showing a heightened CVD risk for middle-aged PLHIVs, compared to age-matched HIV-uninfected individuals, even after correcting for traditional CVD risk factors (Boccara et al. 2013). If the relative risk of all CVDs is $\sim 1.5$-fold higher for PLHIVs than age-matched, HIV-uninfected individuals, a trend toward its decline in virussuppressed PLHIVs has been observed over recent calendar periods in the modern cART era (Klein et al. 2015). For example, the more recent myocardial infarction incidence for cART-treated male and female PLHIVs in France is 1.12- and 1.99fold higher, respectively, than the general population (Baldé et al. 2019). Both HIV-related factors and antiretrovirals might contribute independently to enhancing the CVD risk, together with overrepresentation of CVD risk factors (Lang et al. 2012). In the general population, CVDs - including hypertension, CAD, atrial fibrillation (AF), and chronic heart failure - are associated with cognitive impairment and dementia (Abete et al. 2014). Primary and secondary CVD and risk factor prevention might have been factors contributing to the decline of the dementia incidence over the last three decades (Satizabal et al. 2016). At the same time, emerging evidence suggests that cART-treated PLHIVs have worse cognitive performances that might partly be explained by current or past CVD (Wright et al. 2010; 
Becker et al. 2009; Schouten et al. 2016). Notably, PLHIVs with well-controlled infections and preexisting CVD had sixfold higher odds of having neurocognitive impairment, after adjustment for age, sex, race/ethnicity, education, location, prior acquired immunodeficiency syndrome (AIDS), and total cholesterol (Wright et al. 2010).

\subsection{Atrial Fibrillation}

$\mathrm{AF}$ has been recognized as the most prevalent sustained arrhythmia (Sepehri Shamloo et al. 2019). In the general population, AF is associated with cognitive impairment independently of stroke and/or a number of shared risk factors (Sepehri Shamloo et al. 2019; Madhavan et al. 2018). According to the Rotterdam study (Ott et al. 1997), for a person with $\mathrm{AF}$, the odds ratios (OR) were 1.7 (95\% confidence interval (CI): 1.2-2.5) for developing cognitive impairment or 2.3 (95\% CI: 1.4-3.7) for dementia. The advanced mechanism underlying the AF-cognitive impairment relationship is the high frequency of silent cerebral infarcts, but altered cerebral blood flow, cerebral small-vessel diseases (CSVDs), and especially, cerebral microbleeds, vascular inflammation, and genetic factors have also been underscored (Pastori et al. 2019).

According to epidemiological data, the AF incidence for PLHIVs is increasing, likely due to their advancing age and increasing rates of left ventricular hypertrophy (Hsu et al. 2013). Indeed, the AF frequency was higher for a recent PLHIV cohort than matched, uninfected controls in unadjusted analyses (OR, 1.27; 95\% CI, 0.99-1.64). However, that association was no longer significant after adjusting for demographic parameters and CVD risk factors and was mainly driven by CD4+ T-cell nadir $<200 \mu \mathrm{L}$ (Sanders et al. 2018). We did not find any study evaluating the AF impact on HAND. A recent meta-analysis found $2.0-5.13 \%$ AF prevalence in PLHIVs, with an incidence rate of 3.6/1,000 person-years (Pastori et al. 2019). Low CD4+ T-cell counts $(<200-250$ cells $/ \mu \mathrm{L})$ and high plVLs were predictors of AF (Pastori et al. 2019).

\subsection{Hypertension}

In the general population, hypertension is a major public health problem affecting millions of adults worldwide. Major effects of arterial hypertension on the nervous system are related to CSVD, which represents the damage done to small perforating arteries, a well-known pathway to recurrent strokes, and cognitive loss (Blanco et al. 2017). However, the association of BP with cognitive impairment varies considerably with age and duration of follow-up (O'Callaghan and Kenny 2016). Moreover, plotting that association yields a U-shaped curve (Abete et al. 2014; McNicholas et al. 2018). Indeed, both hypertension and hypotension are associated with poorer 
cognitive performances (Abete et al. 2014; McNicholas et al. 2018). Higher diastolic blood pressure (DBP) - but not systolic blood pressure (SBP) - was previously associated with cognitive impairment (Abete et al. 2014; Tsivgoulis et al. 2009). In contrast, a recent meta-analysis showed that only midlife higher SBP - but not DBP - was associated with the risk of Alzheimer's disease (Lennon et al. 2019). The mechanism by which hypertension leads independently to cognitive decline remains unclear, and sustained hypertension-induced arterial stiffness has been advanced as a possible cause. Atherosclerosis, hypotension, and excessive hypertensive treatment(s) may also induce cerebral hypoperfusion, ischemia, and hypoxemia, in turn leading to neurodegeneration and cognitive impairment (Abete et al. 2014). General population results from recent randomized clinical trials indicate that intensive BP-lowering attenuates cognitive decline (Yang and Williamson 2019). However, continued follow-up of SPRINT-MIND-trial participants is still crucial to evaluate the full spectrum of the effect of intensive BP control (Ambrosius et al. 2014; The SPRINT MIND, Investigators for the SPRINT Research Group, et al. 2019).

The hypertension-HAND relationship in cART-treated adult PLHIVs appears to be as complex as in the general population and also related to the burden of brain white-matter hyperintensities (WMHs), a marker of CSVD (Su et al. 2016). According to SMART study results, antihypertensive drug use was significantly associated with poorer cognitive performance (Wright et al. 2010). However, in another study, multivariable analyses failed to retain the significant hypertensionpoorer cognitive performances association found in univariable analyses (Fabbiani et al. 2013). Also, in cross-sectional (Bonnet et al. 2013) and longitudinal studies (Dufouil et al. 2015) on cART-treated PLHIVs with undetectable HIV, hypertension was not associated with HAND in fully adjusted models. Higher DBP was associated with more extensive cerebral WMHs, one of the cardinal primary CSVD lesions (Ambrosius et al. 2014). The role of hypertension in HAND has not yet been fully elucidated. The apparent implication of vascular disease and its risk factors in HAND might suggest that strategies targeting the vascular system might provide effective mechanisms to prevent cognitive loss in PLHIVs.

\subsection{Coronary Artery Disease}

In the general population, CAD or myocardial infarction is associated with poorer general cognition and loss of verbal fluency, but the pathogenetic mechanism of that association remains elusive (Burkauskas et al. 2018; Sundbøll 2018). CAD per se may lead to AF and heightened platelet activation, which, in turn, might trigger perivascular inflammation in the brain (Burkauskas et al. 2018; Frazier et al. 2014). Overall, it is estimated that cART-treated PLHIVs are at 1.5-fold higher risk of clinical and subclinical CAD, with men having a lower relative risk (1.12) than women (1.99), compared to HIV-negative individuals (Boccara et al. 2013; Baldé et al. 2019). However, a recent study showed that the myocardial infarction relative 
risk is no longer elevated among PLHIVs with immune recovery and controlled plVL on cART, be they men or women (Baldé et al. 2019). This decreasing trend of the myocardial infarction risk might be due to earlier treatment initiation with less toxic drugs and the resulting improvement of immunological status. Determinations of coronary artery-calcium accumulation indicate that the mean vascular age of $>40 \%$ of PLHIVs exceeds by 15 years their chronological age (Guaraldi et al. 2009). Results of the Multicenter AIDS Cohort Study (MACS) and CVD substudy showed that abnormally high coronary artery-calcification levels increased the risk of poorer cognitive performance (Becker et al. 2009). No specific study has evaluated the CAD-HAND association.

\subsection{Carotid Intima-Media Thickness (cIMT)}

In the general population, despite conflicting findings, cIMT, a subclinical marker of atherosclerosis, has usually been associated with diminished cognitive performance in individuals without vascular and neurological diseases (Frazier et al. 2014; Zhong et al. 2012). Some findings suggested an accelerated-atherosclerosis process in cART-treated middle-aged PLHIVs attributable to multiple factors, including higher prevalence (compared to HIV-uninfected individuals) of conventional risk factors, emerging risk factors (chronic inflammation, immune activation, and HIV-infectionrelated senescence), and a deleterious cART role (Lang et al. 2015).

Indeed, using cIMT measurements to assess PLHIVs' increased atherosclerosis risk, it was found that $\sim 25 \%$ of them had carotid plaques significantly associated with three independent risk factors: older age, hypertension, or higher low-density lipoprotein cholesterol (LDL-C) levels (Jeong et al. 2013). A recent meta-analysis showed that middle-aged and aged PLHIVs and their matched HIV-uninfected individuals had similar cIMTs, suggesting that the HIV effect on carotid structure varies primarily according to age (Hanna et al. 2016). However, those findings associated with older PLHIVs may be explained by a survival effect, that is to say, a switch to favorable health behaviors or other parameters enabling their long-term survival despite HIV infection (Hanna et al. 2016). Nonetheless, that parallel in the PLHIVs is in keeping with recent general population findings showing that cIMT is strongly and linearly age-related and that the relationship is not affected by CVD or CV risk factors (van den Munckhof et al. 2018). cIMT was independently associated with PLHIVs' poorer cognitive performance and an independent risk factor for memory impairment at 2 years of follow-up (Fabbiani et al. 2013; Becker et al. 2009; Ciccarelli et al. 2014). 


\section{Metabolic Syndrome}

MetS is characterized by the combination of central obesity, dysglycemia, dyslipidemia, and arterial hypertension. Among the MetS definitions that have been devised, the National Cholesterol Education Program Adult Treatment Panel III (NCEP/ATP III) is applied the most. According to NCEP/ATP III, individuals are considered to have MetS when they meet at least three of the following criteria: (1) waist circumference, as measure of abdominal obesity, of $\geq 102 \mathrm{~cm}$ for men and $\geq 88 \mathrm{~cm}$ for women; (2) triglycerides $\geq 1.70 \mathrm{mmol} / \mathrm{L}$ or being treated for elevated triglyceride levels; and (3) high-density lipoprotein cholesterol (HDL-C) $<1.03 \mathrm{mmol} / \mathrm{L}$ for men and $<1.29 \mathrm{mmol} / \mathrm{L}$ for women or being treated for low HDL-C (Calò et al. 2013); BP $\geq 130 / 85$ mm Hg or on antihypertensive medication; and (Lang et al. 2015) fasting plasma glucose $\geq 5.6 \mathrm{mmol} / \mathrm{L}$ or taking antihyperglycemic agents (Daskalopoulou et al. 2006). Unlike the NCEP/ATP III definition, the World Health Organization (WHO) criteria (Alberti and Zimmet 1998) and the European Group for the Study of Insulin Resistance (EGIR) criteria (Balkau et al. 2002) include insulin resistance or hyperinsulinemia, because clear evidence strongly supports that they play a causal role in most patients' MetSs (Reaven 1988).

Therefore, MetS prevalence strongly depends on the studied population (age, sex, ethnicity, etc.) and the definition applied. If approximately one-third of the American and one-fifth of the European general and adult HIV-infected populations have MetSs (Pal and Ellis 2010; Calza et al. 2017), according to the National Health and Nutrition Examination Survey (NHANES) 2003-2006 cohort, MetS prevalence was found to differ according to sex and to increase with age and for men and women, respectively: 20 and 16\%<40 years old, 41 and 37\% 40-59 years old, and 52 and $54 \% \geq 60$ years (Ervin 2009). Their respective MetS prevalences in the French general population are $23.0 \%$ and $16.9 \%$ (Grundy 2008). It rises even more dramatically as the BMI increases, and overweight men and women were found, respectively, to be $>6$ and $>5.5$ times as likely to meet MetS criteria compared to underweight and normal-weight individuals (Ervin 2009; Grundy 2008).

Most studies on the general population reported that MetS and its components negatively impact cognition (Yates et al. 2012; Muller et al. 2007; Yaffe et al. 2004, 2007). However, findings may vary by sex, with men being more affected in some reports (Cavalieri et al. 2010), women in others (Schuur et al. 2010), and some reporting no differences (Hassenstab et al. 2010), was not only not observed in other studies (Muller et al. 2007), but MetS might even be protective against cognitive decline in older adults (van den Berg et al. 2007). Findings were hampered by the short follow-up and, above all, the failure to include or seek the following confounding factors affecting outcomes in many studies: a significantly higher MetS risk for PLHIVs is associated with demographic and behavioral factors, such as sedentary lifestyle and/or absence of leisure activities; having lower education level and/or socioeconomic status; experiencing financial difficulties; or living without a partner (Costa et al. 2019; Wijndaele et al. 2009; Nobre et al. 2018). 
Hence, adjustment for socioeconomic factors, rarely included in statistical models, significantly attenuated the MetS-cognition association, highlighting the importance of socioeconomic stratum in identifying and targeting risk factors for an individual's cognitive decline (Akbaraly et al. 2010).

The relative contributions of MetS's primary components to cognition have varied across studies. Hypertension, diabetes, obesity, hypertriglyceridemia, and impaired glucose tolerance have been individually associated with cognitive impairment, but the relationship between each metabolic risk factor and cognition is complex (Noble et al. 2012; Dye et al. 2017; Czuriga-Kovács et al. 2016; Morley 2014). It is unknown if MetS relationships with cognition simply reflect the effects of one or two dominant MetS components rather than a synergistic effect of several of them (Crichton et al. 2012). Hence, the MetS-cognitive impairment association might be mainly driven by the inclusion of individuals with diabetes (Creavin et al. 2012). The underlying mechanisms by which MetS is thought to affect cognition are not completely understood (Borshchev et al. 2019). As recently analyzed in the general population, the clustering of MetS factors may induce structural and functional alterations in the brain vasculature, resulting in the development of CSVD with potential effects on cerebral blood flow and cognition (Mellendijk et al. 2015; Alberti et al. 2009).

One study on PLHIVs found that MetS had an independent significant effect on global neurocognitive deficits, not found among the HIV-uninfected controls (Yu et al. 2019). In that study, MetS was more strongly associated with learning, fine motor skills, and executive function (Yu et al. 2019). However, it was hampered by well-known and powerful confounding effects of several variables on vascular disease markers and cognition (Yu et al. 2019). Sex, ethnicity, educational level (all $p=0.02$ ), any lifetime substance abuse disorder, and current and lifetime major depression (both $p<0.001$ ) all differed significantly between PLHIVs and the control group (Yu et al. 2019).

\subsection{Diabetes}

Among MetS criteria, diabetes has most constantly been associated with the development of cognitive dysfunction in non-HIV elderly. Although the mechanisms driving that diabetes-related cognitive dysfunction in the general population are not completely elucidated, the main hypothesis is that insulin resistance can somehow lead to CSVD (Yin et al. 2014). However, recent studies have shown a bidirectional association between severe mood disorders and diabetes mellitus, both factors strongly associated with cognitive impairment (Khaledi et al. 2019; Atique-UrRehman and Neill 2019). In the majority of the studies, the potential confounding effect of concomitant depression has not been well-controlled in diabetic patients.

For PLHIVs, ART is the most incriminated risk factor for the development of diabetes mellitus through diverse mechanisms, depending on the drugs, leading to insulin resistance and increased inflammatory status (Noubissi et al. 2018). 
However, the high frequency of type 2 diabetes mainly seen with first-generation ART has been mostly resolved with newer molecules (Lagathu et al. 2019). However, insulin resistance is still prevalent, possibly as a result of previous fat alterations, ongoing weight gain observed worldwide, and/or truncal adiposity associated with aging (Lagathu et al. 2019). Diabetes and insulin resistance have been associated with PLHIVs' poorer cognitive abilities, and that relationship was stronger for older adults (Dufouil et al. 2015; Yu et al. 2019; McCutchan et al. 2012; Wright et al. 2015; Yang et al. 2018; Khuder et al. 2019). Increased insulin resistance was associated with more severe cognitive impairment in the Hawaii Aging with HIV Cohort studies (Valcour et al. 2005, 2006). However, in those studies, 50\% of PLHIVs had detectable plVL - a situation that hampers extrapolation to current virus-controlled PLHIVs (Khuder et al. 2019; Valcour et al. 2005, 2006). Diabetes in cART-treated PLHIVs, with plVL $<500$ copies/mL, seems to negatively impact all cognitive domains, including memory, executive functions, attention, psychomotor speed, language, and manual dexterity (Dufouil et al. 2015; Yu et al. 2019). Notably, PLHIVs with well-controlled plasma virus replication ( $84 \%$ with HIV RNA $<50$ copies $/ \mathrm{mL}$ ) exhibited the same findings, with the exception of the language domain (Fabbiani et al. 2013). Over 2 years of follow-up and based on only a limited number of tests, diabetic PLHIVs had slightly greater deterioration of executive and memory functions (Dufouil et al. 2015). As for the general population, the mechanism through which diabetes can engender cognitive decay remains to be fully elucidated in PLHIVs: damage to the cerebral arteries or impaired brain-glucose metabolism. Another possible explanation is altered permeability of the blood-brain barrier (BBB) by HIV proteins, thereby potentially increasing brain exposure to higher glucose levels (McCutchan et al. 2012). Nakamoto et al. (2012) observed abnormal microstructural caudate and hippocampus changes associated with irregular glucose metabolism in aging PLHIVs. According to a recent study, diabetic PLHIVs have significantly greater WMH volumes, a CSVD feature, than nondiabetic PLHIVs and HIV-uninfected individuals (Wu et al. 2018). WMHs are associated with worse cognitive performances by cART-treated PLHIVs (Su et al. 2016).

\subsection{Obesity}

A growing body of evidence shows that, for the general population, being overweight or obese in midlife, as assessed with BMI or central adiposity (waist circumference), and a rising BMI curve throughout life, have been associated with brain atrophy, white-matter changes, BBB integrity, and risk of all-cause late-onset dementia and Alzheimer's disease (Kiliaan et al. 2014; Emmerzaal et al. 2015). Hence, an approximately twofold higher risk of Alzheimer's disease is associated with midlife obesity defined as BMI $>30 \mathrm{~kg} / \mathrm{m}^{2}$ (Kivipelto et al. 2005). High late-life BMI is associated with a lower risk of cognitive decline and dementia, and the cognition-central obesity relationship for women is complex and nonlinear 
(McCutchan et al. 2012; Kerwin et al. 2011; Cova et al. 2016). Executive function and speed-of-information processing are the cognitive domains most commonly associated with high BMI and central adiposity (Okafor et al. 2017).

An increasing obesity rate for cART-treated PLHIVs in the USA was reported, and recent results based mostly on men $(70 \%)$ showed that two-thirds of PLHIVs were either overweight $(\sim 37 \%)$ or obese $(\sim 28 \%)$ (Becofsky et al. 2016). In France, the obesity frequency is much lower, $5 \%$ for men and $15 \%$ for women (Pourcher et al. 2015). The relationship between elevated BMI obesity and neurocognitive impairment in HIV-infected persons is complex and sometimes contradictory (McCutchan et al. 2012; Gustafson et al. 2013), probably because the odds of having diabetes and hypertension are three and two times higher, respectively, for obese PLHIVs than normal-weight PLHIVs (Becofsky et al. 2016). However, one study's authors considered abdominal obesity per se to be associated with HAND in PLHIVs because the relationship between overweight or obesity and neurocognitive impairment was not attenuated when adjusting for these cardiometabolic factors (Sattler et al. 2015). Obesity - but not overweight - was associated with slowed cognitive processing compared to normal-weight PLHIVs (Okafor et al. 2017). However, that report did not specify the percentage of cART-treated aviremic PLHIVs, whose sample included $40 \%$ of alcohol- and illicit drug-addicted PLHIVs and 34\% with current hepatitis $\mathrm{C}$ virus (HCV) infection.

A study on the MACS cohort, which included immunovirologically wellcontrolled cART-treated PLHIVs, identified no association between regional adipose tissue or anthropometric measurements and neuropsychological evaluation parameters (Lake et al. 2015). In contrast, a recent study also on the MACS cohort found, in its cross-sectional part, that the higher the adiposity, the lower the motorspeed-based cognitive functions (Rubin et al. 2019). Therein, BMI and central obesity were solely associated with motor-function decline evaluated with only one test, whereas it is highly recommended that each cognitive domain be evaluated with at least two different tests (Carey et al. 2004). Analysis of CHARTER study data found a protective effect of higher BMI on a global assessment of neurocognitive impairment, whereas larger waist circumference was predictive of neurocognitive impairment after correcting for a diagnosis of AIDS, diabetes, or elevated serum triglycerides (McCutchan et al. 2012; Sattler et al. 2015). However, McCutchan et al. (2012) reported detectable plasma and cerebrospinal fluid (CSF) HIV loads in $35 \%$ and $17 \%$ of cART-treated PLHIVs, respectively. Sattler et al. (2015) found that $20 \%$ of PLHIVs had detectable plVLs, but obese and nonobese groups may not have been well-matched, thereby introducing bias, because sex, plVLs, and current CD4+ T-cell counts differed significantly between groups. Moreover, the third nonobese group's BMI quartile was $31 \mathrm{~kg} / \mathrm{m}^{2}$ as opposed to the first obese group's quartile of $22 \mathrm{~kg} / \mathrm{m}^{2}$ (Sattler et al. 2015).

Another study that evaluated specific neurocognitive domains of HIV-infected women found no significant association between midlife obesity, compared to normal weight, for processing speed (Gustafson et al. 2013). However, obesity was associated therein with better performance on the Trail-Making Test B, but worse performance on the Stroop Interference task, two assessments exploring 
executive functions. A study on HIV-infected men in the MACS cohort found longitudinal associations between BMI obesity and less decline in motor function with increasing age versus those with a normal $(p=0.04)$ or overweight $(p=0.05)$ BMI (Rubin et al. 2019). A similar trend ( $p=0.07)$ was observed between central obesity and motor function (Rubin et al. 2019). A critical review of that MACS report also raised its hypothetical nature because of the absence of a temporal association between HIV-disease markers and adiposity (Cysique et al. 2019). All those findings may also be explained by differences in study populations and the presence of other cofounding comorbidities, including current HCV coinfection, for instance (Okafor et al. 2017). Systemic and central nervous system immuneinflammatory factors were thought to mediate the relationship between increased body fat or obesity and cognitive impairment (Sattler et al. 2015), but that hypothesis was not confirmed by other studies (Okafor et al. 2017). Therefore, further studies are warranted to determine the potential impact of BMI on PLHIVs' cognition.

\subsection{Dyslipidemia}

The dyslipidemia-cognition relationship in the general population is complex and varies considerably, depending mainly on the age at which cholesterol is measured. Longitudinal and cross-sectional studies have revealed associations between high LDL-C or total cholesterol levels and cognitive impairment (Yaffe et al. 2002; Ma et al. 2017). In contrast, other large studies on older adults found an association between higher triglycerides (Yin et al. 2012) or LDL-C and better cognitive performance ( $\mathrm{Lv}$ et al. 2016).

Dyslipidemia is common in PLHIVs. Hypercholesterolemia was associated with poorer cognitive performance in the INSIGHT SMART study (Wright et al. 2010). Longitudinal study results showed an association between dyslipidemia and cognitive impairment in cART-treated PLHIVs with well-controlled HIV infection (Ciccarelli et al. 2014; Sacktor et al. 2016; Mukerji et al. 2016). Indeed, within the MACS cohort, hypercholesterolemia almost tripled the risk for worsening HAND stage during the 4 years of follow-up (Sacktor et al. 2016). For PLHIVs with elevated cholesterol levels, higher HDL-C and statin use were associated with a slower rate of cognitive decline (Mukerji et al. 2016). Hyperlipidemia was weakly associated with HAND in older ( $>55$ years) but not younger PLHIVs in a crosssectional study on PLHIVs, whose cART failed to achieve virus suppression (Fogel et al. 2015). However, blood HDL- and LDL-C levels were not significantly associated with HAND in the CHARTER cohort (McCutchan et al. 2012). Notably, ancillary CHARTER studies often included high percentages of PLHIVs with unsuppressed plasma and CSF HIV RNA. However, in that study, one-third of the patients had detectable plasma and 17\% CSF HIV loads. Pertinently, those studies may not be representative of PLHIVs in Western countries, the vast majority of whom receive suppressive cART. Moreover, $86 \%$ of PLHIVs on cART achieved 
viral suppression in the 2019 worldwide UNAIDS data (aidsinfo.unaids.org), confirming that their data are not applicable to a majority of countries today.

\section{The Concept of Vascular Cognitive Impairment (VCI)}

VCI refers to a syndrome with evidence of clinical stroke or subclinical vascular brain pathologies that contribute to any degree of cognitive impairment affecting at least one cognitive domain, and ranging from subjective cognitive decline to dementia, the most severe form of VCI (van der Flier et al. 2018; Gorelick et al. 2011). Diagnosing VCI involves two steps: establishing the presence of a cognitive impairment by a comprehensive neuropsychological assessment and confirming that it results directly from brain vascular injury (Gorelick et al. 2011). However, VCI diagnosis is hampered by the lack of standardization of diagnostic criteria (van der Flier et al. 2018; Wiederkehr et al. 2008a, b; Sachdev et al. 2014). Hence, the prevalence of early-onset vascular dementia (in patients $<65$ years old) ranges from 3.1 to $44 \%$ in several studies (Cosentino et al. 2004), with those differences mainly reflecting inconsistent diagnostic criteria, diverse sampling methods, and patient or country demographic disparities (Khan et al. 2016).

To date, VCI-diagnostic criteria have been proposed by at least six organizations, each with disparate levels of proof and agreement: the National Institute of Neurological Disorders and Stroke (NINDS) and the Association Internationale pour la Recherche et l'Enseignement en Neurosciences (AIREN), the State of California Alzheimer's Disease Diagnostic and Treatment Centers (ADDTC), Diagnostic and Statistical Manual of Mental Disorder-5 (DSM-5), the American Heart Association (AHA) and the American Stroke Association (ASA) scientific statement on vascular contributions to cognitive impairment and dementia, the Vascular Impairment of Cognition Classification Consensus Study (VICCCS-2), and the Vascular Behavioral and Cognitive Disorders (VASCOG) (van der Flier et al. 2018; Gorelick et al. 2011; Sachdev et al. 2014; Khan et al. 2016). The patient, an informant, or clinician must note "subjective cognitive complaints" as a recent requirement specific to the VASCOG and DSM-5 criteria.

The neuroimaging criteria, available for VASCOG, NINDS-AIREN, and ADDTC criteria, differ markedly. Reviews of clinical-pathological studies comparing various diagnostic criteria for vascular dementia showed that their sensitivity (average 50-56\%) and specificity (range 64-98\%, average 87\%) varied widely, with interrater reliability differing broadly, and thus their incidence, prevalence, and frequency rates as well (Wiederkehr et al. 2008a, b; Jellinger 2013). Devised after those reviews, the VASCOG and DSM-5 criteria appear to be more sensitive, while the NINDS-AIREN criteria are more specific and recommended for research purposes (van der Flier et al. 2018; Sachdev et al. 2014). Aiming for simplification, the VICCS-2 criteria have proposed referring only to mild or major VCI (Skrobot et al. 2018), with mild VCI defined as impairment of at least one cognitive domain and mild-to-no impairment of activities of daily living, and major VCI referring to 
significant deficits in at least one cognitive domain and severe disruption of those activities. However, several teams invalidated the impairment in at least one cognitive domain criterion for VCI because it resulted in a high false-positive rate, even when using the fifth percentile cutoff (i.e., 1.65 standard deviation [SD]) to dichotomize each domain score and proposed retaining at least two impaired cognitive domains (Barbay et al. 2018a; Godefroy et al. 2013). The choice of the threshold also significantly influences the true prevalence of cognitive impairment, with a strong benefit for the fifth percentile cutoff (Barbay et al. 2018a, 2018b). The frequently used 1.5-SD cutoff provides similar estimated prevalences at the cost of slightly more false positives (Barbay et al. 2018b). However, the 1-SD cutoff, used to define HAND, induces an unreasonably high false-positive VCI rate $(>20-30 \%)$ (Barbay et al. 2018b; Antinori et al. 2007; Underwood et al. 2019).

\subsection{Stroke}

Cerebrovascular diseases are a leading cause of death and disability worldwide. Vascular risk-factor impact on the brain can result in clinically silent disease or overt stroke, all of which lead to cognitive impairment and frailty. During HIV infection, ischemic strokes are much more common than cerebral hemorrhage, the latter affecting mainly PLHIV intravenous-drug abusers (Rasmussen et al. 2011). Currently, the TOAST (Trial of ORG 10172 in acute stroke treatment) classification scheme is the most widely accepted ischemic stroke-subtyping system internationally (Adams and Biller 2015). This simple system describes five major stroke subtypes: large artery atherosclerosis, cardioembolism, CSVD, stroke of other determined cause, and stroke of undetermined cause. The authors of several studies reported an association between HIV infection and the risk of stroke (Rasmussen et al. 2011; Benjamin et al. 2012; Chow et al. 2014a, b; Sico et al. 2015; Ovbiagele and Nath 2011; Moulignier et al. 2015). According to a cART-era meta-analysis, the rate of stroke during a 4-year median period was $1.78 \%$ for PLHIVs, whereas ischemic stroke incidence for non-HIV individuals $<64$ years old was $0.08 \%$ per year and $0.24 \%$ at 4 years (D'Ascenzo et al. 2015). However, the results of those studies were rather heterogeneous in terms of methodology, ethnicity, HIV-HCV coinfection, and drug abuse.

Ethnic differences in stroke risk are widely recognized and are an important parameter of incidence variability, even greater for younger populations (Chong and Sacco 2005). Hence, in a large clinical cohort study conducted in the Southeastern USA with a majority of African-American patients, the ischemic stroke incidence was 1.5 times the rate of a population-based cohort in North Carolina (Vinikoor et al. 2013). In Europe, PLHIVs have a slightly lower stroke incidence than in the USA, consistent with lower rates seen in the general population of Europe compared to the USA (Vinikoor et al. 2013; Corral et al. 2009). More recent studies revealed a decline in the stroke risk among PLHIVs in recent years after the introduction of cART (Alvaro-Meca et al. 2017; Lin et al. 2019). There may be 
many reasons for this decline: adverse events associated with older antiretroviral regimens or more effective cART in the recent era, higher CD4+ T-cell nadir, lower frequency of opportunistic infections, and overestimated misdiagnoses due to limited diagnostic tests during the earlier period of the infection. Hence, as observed for myocardial infarction (Baldé et al. 2019), ischemic stroke incidence in PLHIVs with high CD4+ T-cell counts or low HIV RNA is similar to that of HIV-negative individuals (Marcus et al. 2014).

Hypertensive CSVD and large artery atherosclerosis are the main risk factors for these infarcts in PLHIVs (Du and Xu 2019). A higher risk of stroke of undetermined etiology in cART-treated PLHIVs compared to age-matched uninfected individuals found in one study (Chow et al. 2017) was hampered by the failure to comply with the thorough investigations recommended in this setting (Vizzardi et al. 2013; Hart et al. 2017), with 63\% immunovirologically uncontrolled PLHIVs within the 6 months preceding the event, $47 \%$ of African-American individuals and potential factors contributing to stroke (e.g., 38\% cocaine and 17\% methamphetamine current users). Indeed, according to the Baltimore-Washington Cooperative Young Stroke Study, any drug use was found for $22 \%$ of strokes occurring in young individuals, and African-Americans were significantly more likely to have recent drug use than Caucasians (Chong and Sacco 2005; Sloan et al. 1998).

The results of numerous studies on the general population have highlighted that the prevalence of cognitive impairment after stroke is high, especially after stroke recurrence, and demographic factors, like age, education, and occupation, as well as hypertension, diet, and physical activity, all play significant roles (Lo Coco et al. 2016). Most recent findings support the notion that cognitive impairment in elderly individuals with stroke is likely the result of a synergistic interplay between neurodegenerative changes that progressively occur in many cerebral regions and vascular injuries. We did not find any study evaluating the stroke impact on HAND, but it should not be different from what is observed in the general population.

\subsection{Cerebral Small-Vessel Disease}

CSVD is defined by a range of neuroimaging, pathological, and associated clinical abnormalities, which may be associated with subtle physical and cognitive function deficits that often go unnoticed, thought to originate from a disease process modifying perforating cerebral arterioles, capillaries, and venules (Wardlaw et al. 2013a; Cuadrado-Godia et al. 2018; Li et al. 2018). CSVD is one of the major mechanisms underlying cognitive decline, frailty, and altered gait, and it is the second cause of dementia in seniors (Wardlaw et al. 2013a; Pantoni 2010; Charidimou et al. 2016; Greenberg 2006). It has been implicated in $25 \%$ of strokes and as more than doubling the risk of stroke recurrence (Pantoni 2010). CSVD is significantly associated with neurodegenerative diseases (e.g., Alzheimer's disease) and might even be the primary mechanism of cognitive decline attributed to vascular risk factors (Wardlaw et al. 2013a). Although the best known magnetic resonance imaging 
(MRI) characteristics of CSVD are WMHs of presumed vascular origin, silent brain infarcts and cerebral microbleeds, recent small subcortical infarcts, and prominent perivascular spaces were more recently identified as being attributable to CSVD (Wardlaw et al. 2013b). To better characterize and differentiate CSVD-surrogate WMHs from WMHs of another origin, the STandards for ReportIng Vascular changes on Euroimaging (STRIVE) criteria have attempted to standardize CSVD neuroimaging (Wardlaw et al. 2013b). For the most part, the pathogenetic mechanism underlying CSVD remains unknown, and data are still insufficient to establish whether inflammation is causal of, or secondary to, CSVD (Low et al. 2019).

Age and hypertension are the most frequently cited major risk factors, while CVD and MetS are the more discussed risk factors (Wardlaw et al. 2013a; Pantoni 2010). The role of dyslipidemia has not yet been clearly elucidated, with hyperlipidemia associated with either a higher (Lin et al. 2017) or lower WMH burden (JimenezConde et al. 2010). A proof-of-principle study found no difference between WMH volumes in diabetic and matched nondiabetic individuals (Utrecht Vascular Cognitive Impairment Study Group et al. 2018). Recent evidence strongly suggests that CSVD development and progression may result from altered immune homeostasis in the central nervous system, leading to endothelial failure, astrogliosis, and microglial activation and, thus, to neurovascular unit dysfunction (Kaiser et al. 2014; Shoamanesh et al. 2015).

The authors of numerous publications have described a vascular WMH-cognitive deterioration association in the general population (Pantoni et al. 2015; Chui and Ramirez 2017; Cannistraro et al. 2019). The results of longitudinal studies suggested that individuals with less white-matter integrity of vascular origin at baseline are more likely to progress to cognitive impairment or Alzheimer's disease than are those with more white-matter integrity (Zhuang et al. 2012; Wardlaw et al. 2015). However, while extensive WMHs (Fazekas grade 3) are associated with VCI, the relationship between mild-to-moderate WMH burden (Fazekas grade 1-2) and cognition, especially when it is the sole CSVD parameter, is much less clear (Jellinger 2013; Dey et al. 2019). Moreover, as mentioned above, in the general population, no uniform diagnostic criteria exist for CSVD-associated cognitive impairment, and predicting which individuals with CSVD will progress to cognitive decay has proven difficult (Cannistraro et al. 2019). MRI and serum biomarkers are currently being investigated but are not yet available for routine use in clinical practice. Cognitive reserve significantly affects the strength of the association between WMHs and cognitive change over time, with less education associated with a stronger influence of WMHs on processing speed, while higher education attenuated this relationship (Jokinen et al. 2009, 2016). Finally, differentiating CSVD cognitive decline from mood disorder is also a clinical challenge. Hence, as in the general population, acknowledging WMHs as the link to cognitive decay in PLHIVs requires controlling numerous confounding factors.

CSVD prevalence is doubled in cART-treated immunovirologically suppressed middle-aged PLHIVs compared to age-matched HIV-uninfected individuals (Moulignier et al. 2018; Trentalange et al. 2018). Advancing age and hypertension the two major risk factors for WMHs in the general population - were also identified 
in the majority of studies on PLHIVs (Su et al. 2016; Moulignier et al. 2018; van Zoest et al. 2018), sometimes along with the effects of AIDS or prior profound immunodeficiency (Moulignier et al. 2018; van Zoest et al. 2018), neuroinflammation (van Zoest et al. 2018), or diabetes (Wu et al. 2018). The lack of a detrimental effect of exposure to any ART-drug class on CSVD risk was reported in two studies analyzing the determinants of WMHs of presumed vascular origin in cART-treated PLHIVs with sustained and suppressed plVLs and immune recovery, after accounting for traditional and HIV-specific CV risk factors (Su et al. 2016; Januel et al. 2019). On the other hand, a significant association between protease inhibitors and CSVD was found in two autopsy studies (Soontornniyomkij et al. 2014; Morgello et al. 2014). However, those studies were differently hampered by the lack of a matched control group (Soontornniyomkij et al. 2014) and the time since HIV diagnosis/on cART (Morgello et al. 2014), insufficient data on CD4+ T-cell counts and/or plVLs (Soontornniyomkij et al. 2014), the high percentage of immunovirologically uncontrolled PLHIVs (Soontornniyomkij et al. 2014; Morgello et al. 2014), and potential contributors to CSVD (e.g., current cocaine use and HCV coinfection) (Soontornniyomkij et al. 2014; Morgello et al. 2014).

MRI-visualized white-matter injury in PLHIVs is associated with different underlying pathological features, and WMHs of presumed vascular origin, strictly defined by STRIVE criteria, are only one of them (Su et al. 2016; Moulignier et al. 2018). CVSD-surrogate WMHs are usually distributed bilaterally in the white matter, including the pons and brainstem, and are also seen in deep gray matter. They appear hyperintense compared to the normal brain on T2-weighted or fluidattenuated inversion recovery (FLAIR) MRI and can be patchy or confluent depending on their severity stage (Fazekas et al. 1987; Shi and Wardlaw 2016). Imaging studies of HIV encephalopathy show diffuse bilateral and symmetric periventricular WMHs, preferentially affecting the more central white matter, without mass effect or enhancement, far different from CSVD (Sarbu et al. 2016). Whitematter changes noted during the pre- and early-ART era were associated with the AIDS-dementia complex, defined as cognitive, motor, and behavioral neurological impairments not attributable to opportunistic infections (Navia et al. 1986), and were histologically characterized by myelin pallor, gliosis, and leukoencephalopathy (Davies et al. 1997; Everall et al. 2005). Should those changes remain predominant in the post-cART era, they might possibly reflect the remaining legacy of HIV infection preceding the cART era, ART toxicities, or medical comorbidities (Jensen et al. 2019). Those WMHs have been correlated with lower fractional anisotropy values, consistent with disrupted organization of white-matter tracts (Kochunov et al. 2007). Diffusion-tensor imaging and fractional anisotropy-characterized WMHs in cART-treated PLHIVs with fully controlled HIV infections were independently associated with hypertension and also higher concentrations of monocyteactivation biomarkers in CSF, suggesting that WMHs likely reflect the influence of ongoing neuroinflammation independent of HIV infection (van Zoest et al. 2018). Those findings have been reproduced in transgenic rodent models, and increased mean diffusivity in diffusion-tensor imaging and lower fractional anisotropy values within the corpus callosum were associated with demyelination and increased 
space between white-matter tracts and pathological hallmarks of HIV encephalopathy (Lentz et al. 2014). Advanced etiologies include demyelination, neuroinflammation/oxidative stress, synaptodendritic injury, ART toxicities, and microvascular alterations (Alakkas et al. 2019).

The neuropathological features of CVSD-surrogate WMHs include axonal loss, enlargement of perivascular spaces, thicker vessel walls, gliosis, myelin loss, increased expression of several hypoxia markers, afferent arteriolar tortuosity, decreased vessel densities, and microglial activation (Gouw et al. 2011). They are caused by arteriosclerosis, lipohyalinosis, and fibrinoid necrosis of small vessels, thereby describing endothelial proliferation, tunica media degeneration, and overall small-vessel wall-thickening (Paradise and Sachdev 2019; Schreiber et al. 2019). Only a few studies have been able to clearly differentiate CVSD-surrogate WMHs from other potential causes of WHMs in HIV-infected persons (Su et al. 2016; Moulignier et al. 2018; Watson et al. 2017). Hence, according to Watson et al. (2017), WMHs typical or atypical of CSVD and mixed distribution types were, respectively, observed in $41 \%, 32 \%$, and $27 \%$ of PLHIVs.

Clinical MRI studies have often focused on separate aspects of CSVD, such as WMHs, and found only weak associations with clinical symptoms (Wardlaw et al. 2013a, 2015; Shi and Wardlaw 2016; Gouw et al. 2011; Paradise and Sachdev 2019). The results of several studies documented the cognitive impact of WMHs on middle-aged and aged cART-treated PLHIVs with long-term virus suppression (Sanford et al. 2019; Su et al. 2016; van Zoest et al. 2018; Watson et al. 2017; Schouten et al. 2016). However, in most people, MRI brain-damage markers of CSVD do not occur alone. Hence, numerous studies on the general population have emphasized that not only WMHs but also lacunes and microbleeds contribute to clinical symptoms, like cognitive decline (Gouw et al. 2011). According to Wardlaw et al. (Wardlaw et al. 2013b, 2015; Shi and Wardlaw 2016), the effect(s) of their combined presence are a better predictor of the cumulative CSVD impact on the brain than each feature alone. The WMHs of presumed vascular origin are the main CSVD feature in PLHIVs, and microbleeds and/or silent brain infarcts are less frequent (Moulignier et al. 2018). Therefore, CSVD should be considered a "whole-brain disease" and MRI markers assessed together with frequently coexisting large-vessel infarcts, to improve understanding of the mechanisms involved in VCI (Gouw et al. 2011).

\subsection{Clinical Implications for HAND Criteria}

The discrepancies among findings, some showing a deleterious and others a beneficial (or no impact) of CVD and/or MetS on cognitive function, may be partly explained by the majority of studies on cART-treated PLHIVs having been conducted using HAND criteria. According to those criteria, estimates of the burden of mild forms of cognitive impairment in PLHIV-cohort studies ranged from 5\% to $>80 \%$ (Vivithanaporn et al. 2010; Simioni et al. 2010). The main stumbling block of 
those Frascati criteria (Antinori et al. 2007) is that they label $>30 \%$ of a normative reference population as cognitively impaired (Underwood et al. 2018), which yields a substantial overestimation of the true proportion of affected participants in a study population, due to their lower-than-expected specificity (On Behalf of the POPPY Study Group et al. 2016; McDonnell et al. 2014; Meyer et al. 2013). Hence, evidence is mounting in support of not using the HAND criteria in the modern cART era in resource-rich settings, and updated standards, with a threshold of impairment referring to validated normative datasets, are sorely needed (Schouten et al. 2016; Underwood et al. 2018; McDonnell et al. 2014; Meyer et al. 2013; Gisslén et al. 2011; Torti et al. 2011; Nightingale et al. 2014; Saloner and Cysique 2017). Indeed, HIV infection is the only disease for which specific cognitive norms have been proposed $(<1 \mathrm{SD})$. For other diseases with potential cognitive impact also affecting young and middle-aged patients, e.g., multiple sclerosis or inflammatory systemic diseases, standardized neurologically defined norms are currently used (Palta et al. 2016).

Cerebrovascular lesions are frequent in elderly PLHIVs. However, their impact on cognition is not that clear, and while VCI-prevalence rates seem to be high in clinical studies, CSVD is rarely found to correspond neuropathologically to clinical cognitive impairment in postmortem studies. Indeed, CSVD was not described in the National NeuroAIDS Tissue Consortium (NNTC) paper, based on 589 brain samples collected from 1999 to 2008, and only minimal histological changes were correlated to HAND (Everall et al. 2009).

As in the general population, the pathophysiology behind characteristic MRI CSVD findings is still subject to controversy (McAleese et al. 2016). Whether or not CSVD is the leading cause of VCI in the general population and frequent in PLHIVs, works on the mechanisms of inflammation-induced neuronal insults cannot be ignored on the basis of those findings (Caruana et al. 2017). Recent evidence suggests that brain exposure to HIV can directly or indirectly modulate the amyloid and tau pathways (Canet et al. 2018). Neuropathology studies on aged PLHIVs often demonstrated the presence of insoluble protein aggregates that are found in aged brains of the general population, such as $\beta$-amyloid, hyperphosphorylated tau, or $\alpha$-synuclein, in addition to vascular pathologies (Canet et al. 2018). Studies evaluating WMHs and cognition are mainly cross-sectional, so they can only show association rather than directly examine causality.

The numerous VCI criteria have not been validated in the setting of HIV infection. Moreover, recent findings showing a WMH-HAND association tend to confuse CVSD-surrogate WMHs of presumed vascular origin and WMHs of another origin (Lescure et al. 2013; Langford et al. 2002; Gongvatana et al. 2011; Nir et al. 2014). Indeed, WMHs are heterogeneous, and structural white-matter abnormalities observed on brain MR images are not always linked with CSVD (Desai and Mullins 2014; Kanekar and Devgun 2014; Moritani et al. 2014).

With increasing availability of brain MRI, numerous WMHs are being visualized, and distinguishing WMHs due to CSVD from those of multiple sclerosis, other inflammatory brain diseases or metabolic leukodystrophies can be challenging, in the general population and PLHIVs (Alber et al. 2019). While brain MRI is valuable 
to determine the extent of WMHs, its use at elucidating what might be the HIV-related neuropathology substrate in virally suppressed cART-treated PMHIVs is less clear. Some studies on PLHIVs clearly excluded WMHs of presumed vascular origin, retaining only diffuse WMHs, and showed a significant association among the latter, HIV escape in the CSF and cognitive impairment (Kugathasan et al. 2017).

Studies exploring radiological-neuropathological relationships have shown that white-matter loss and WMHs are closely correlated with cytokines and synaptodendritic injury markers, like neuronal microtubule-associated protein-2 (MAP-2), particularly when HIV encephalitis is present (Ellis et al. 2007). A recent meta-analysis of diffusion-tensor imaging, widely used to assess HIV effects on white-matter microarchitecture, has revealed high heterogeneity between studies and relatively small differences (O'Connor et al. 2017). Resting-state functional MRI showed that HAND in virus-suppressed PLHIVs are associated with significantly decreased brain-connectivity networks in the absence of vascular injury (Chaganti et al. 2017). Hence, findings in cART-treated aviremic PLHIVs underlined that widespread WMHs are more suggestive of white-matter demyelination, as described with HIV encephalitis/encephalopathy, than WMH of presumed vascular origin (van Zoest et al. 2018; Underwood et al. 2017).

In the healthy general population, isolated WMHs are also highly prevalent, and it remains unclear whether WMHs are always pathological or clinically insignificant and part of physiological aging (Das et al. 2019). The subcortical or periventricular WMH-distribution pattern is also important for the diagnosis of their vascular origin and rarely described in the HIV literature (Wardlaw et al. 2013b; Alber et al. 2019; Das et al. 2019). Punctate WMHs probably result from a variety of causes and have relatively low risk for further progression (Das et al. 2019). On the other hand, confluent WMHs are likely to progress more aggressively (Das et al. 2019). Only the STRIVE criteria are recognized as the gold standard for CSVD-associated WMHs (Wardlaw et al. 2013b). Finally, mild cognitive impairments according to HAND and VCI criteria differ inherently and do not overlap. Indeed, mild forms of HAND are defined by at least two cognitive domains with $\geq 1.0 \mathrm{SD}$ of cognitive impairment, mild VCI by only at least one cognitive domain but with $\geq 1.65 \mathrm{SD}$ of cognitive impairment in the absence of functional impairment for both criteria (Skrobot et al. 2018; Antinori et al. 2007). To date, no argument supports preferentially choosing VICCS-2 criteria for evaluating HIV-associated cognitive decay rather than the five others.

\section{Conclusion}

With growing evidence that CVD and MetS probably contribute to cognitive impairment in cART-treated PLHIVs with well-sustained virological control, it is essential to improve early detection and encourage appropriate management of these conditions. However, their precise roles remain to be elucidated because several studies included PLHIVs not virologically suppressed and with major confounding 
cognitive impairment risk factors, e.g., ethnically diverse cohorts, heterogeneous ages at which reading was acquired and years of education, current HCV infection, or illicit drug abuse (Saloner and Cysique 2017; Marquine et al. 2018; Haddow et al. 2015). That is why we think that only immunovirologically controlled PLHIVs with $\mathrm{plVL}<50$ copies $/ \mathrm{mL}$ can serve to optimally evaluate the true brain consequences of chronic HIV infection. Moreover, cognitive decline should not be evaluated with HAND criteria but rather with defined neuropsychological norms, as widely acknowledged by neurocognitive specialists who use them in memory clinics (Azam et al. 2016). To date, none of the numerous VCI criteria has been validated for PLHIVs or may be preferentially chosen.

A better definition of WMHs must also be used to identify different WMH subtypes, possibly with different etiologies, outcomes, and clinical significance, which emphasizes the need to comply with the STRIVE neuroimaging standards used in neurovascular trials for CVSD-surrogate WMHs (Wardlaw et al. 2013b). Future studies should also take into account all neuroimaging CSVD markers and include advanced multimodal structural and functional MR sequences with high spatial resolution, to better assess the VCI risk in PLHIVs and its potential participation in cognitive impairment. As Brew (2016) questioned in his editorial in AIDS on Su et al.'s (2016) findings: If HAND is synonymous with VCI, why does evidence, albeit somewhat spotty, support the efficacy of neuro-cART? And why would maraviroc intensification of cART attenuate HAND in sustained immunovirologically suppressed PLHIVs?

Elucidation of cerebrovascular lesion pathophysiology, clarification of characteristic brain-MRI findings, and understanding of the impact of combined parameters are strongly needed to improve the diagnostic accuracy of HIV-associated cognitive impairment. The hypothesis of a unifying pathological mechanism in aviremic aging PLHIVs, based on VCI, albeit attractive, seems too restrictive. Indeed, in the general population, pure $\mathrm{VCI}$ forms or neurodegenerative cognitive impairment is very rare, and a mixture of both is the dominant pathology. CSVD- and HIV-driven neurodegenerative processes may interact, either independently of each other or through additive or synergistic effects on PLHIVs' cognitive decline. Does CSVD merely reduce the cognitive threshold needed for overt clinical cognitive impairment, or do both factors potentiate HAND-specific pathophysiological pathways? A more definite answer as to the relative contributions of these factors at a population level, however, will only come from further large, well-designed, longitudinal studies, supported by neuropathological analyses (Brew 2016).

\section{References}

Abete P, Della-Morte D, Gargiulo G, Basile C, Langellotto A, Galizia G et al (2014) Cognitive impairment and cardiovascular diseases in the elderly. A heart-brain continuum hypothesis. Ageing Res Rev 18:41-52 
Adams HP, Biller J (2015) Classification of subtypes of ischemic stroke: history of the trial of org 10172 in acute stroke treatment classification. Stroke 46(5):114-117

Akbaraly TN, Kivimaki M, Shipley MJ, Tabak AG, Jokela M, Virtanen M et al (2010) Metabolic syndrome over 10 years and cognitive functioning in late midlife: the Whitehall II study. Diabetes Care 33(1):84-89

Akbaraly T, Sexton C, Zsoldos E, Mahmood A, Filippini N, Kerleau C et al (2018) Association of long-term diet quality with hippocampal volume: longitudinal cohort study. Am J Med 131 (11):1372-1381

Alakkas A, Ellis RJ, Watson CW-M, Umlauf A, Heaton RK, Letendre S et al (2019) White matter damage, neuroinflammation, and neuronal integrity in HAND. J Neurovirol 25(1):32-41

Alber J, Alladi S, Bae H-J, Barton DA, Beckett LA, Bell JM et al (2019) White matter hyperintensities in vascular contributions to cognitive impairment and dementia (VCID): knowledge gaps and opportunities. Alzheimers Dement 5:107-117

Alberti KG, Zimmet PZ (1998) Definition, diagnosis and classification of diabetes mellitus and its complications. Part 1: diagnosis and classification of diabetes mellitus provisional report of a WHO consultation. Diabet Med J 15(7):539-553

Alberti KGMM, Eckel RH, Grundy SM, Zimmet PZ, Cleeman JI, Donato KA et al (2009) Harmonizing the metabolic syndrome: a joint interim statement of the international diabetes federation task force on epidemiology and prevention; national heart, lung, and blood institute; American Heart Association; World Heart Federation; International Atherosclerosis Society; and International Association for the Study of Obesity. Circulation 120(16):1640-1645

Alvaro-Meca A, Berenguer J, Díaz A, Micheloud D, Aldámiz-Echevarría T, Fanciulli C et al (2017) Stroke in HIV-infected individuals with and without HCV coinfection in Spain in the combination antiretroviral therapy era. Plos One 12(6):e0179493

Ambrosius WT, Sink KM, Foy CG, Berlowitz DR, Cheung AK, Cushman WC et al (2014) The design and rationale of a multicenter clinical trial comparing two strategies for control of systolic blood pressure: The Systolic Blood Pressure Intervention Trial (SPRINT). Clin Trials J 11 (5):532-546

Antinori A, Arendt G, Becker JT, Brew BJ, Byrd DA, Cherner M et al (2007) Updated research nosology for HIV-associated neurocognitive disorders. Neurology 69(18):1789-1799

Atique-Ur-Rehman H, Neill JC (2019) Cognitive dysfunction in major depression: from assessment to novel therapies. Pharmacol Ther 202:53-71

Azam B, Whitfield TJ, Radford D, Dontham SG, Stevens T, Dannhauser T et al (2016) Trends in referred patient profiles in a memory clinic over 20 years. Dementia 15(4):789-797

Baldé A, Lang S, Wagner A, Ferrières J, Montaye M, Tattevin P et al (2019) Trends in the risk of myocardial infarction among HIV-1-infected individuals relative to the general population in France: impact of gender and immune status. Plos One 14(1):e0210253

Balkau B, Charles M-A, Drivsholm T, Borch-Johnsen K, Wareham N, Yudkin JS et al (2002) Frequency of the WHO metabolic syndrome in European cohorts, and an alternative definition of an insulin resistance syndrome. Diabetes Metab 28(5):364-376

Barbay M, Taillia H, Nédélec-Ciceri C, Bompaire F, Bonnin C, Varvat J et al (2018a) Prevalence of poststroke neurocognitive disorders using National Institute of Neurological disorders and Stroke-Canadian Stroke Network, VASCOG Criteria (Vascular Behavioral and Cognitive Disorders), and optimized criteria of cognitive deficit. Stroke 49(5):1141-1147

Barbay M, Diouf M, Roussel M, Godefroy O, Group G Study (2018b) Systematic review and metaanalysis of prevalence in post-stroke neurocognitive disorders in hospital-based studies. Dement Geriatr Cogn Disord 46(5-6):322-334

Barberger-Gateau P, Raffaitin C, Letenneur L, Berr C, Tzourio C, Dartigues JF et al (2007) Dietary patterns and risk of dementia: the three-city cohort study. Neurology 69(20):1921-1930

Becker JT, Kingsley L, Mullen J, Cohen B, Martin E, Miller EN et al (2009) Vascular risk factors, HIV serostatus, and cognitive dysfunction in gay and bisexual men. Neurology 73 (16):1292-1299 
Becofsky KM, Wing EJ, Wing RR, Richards KE, Gillani FS (2016) Obesity prevalence and related risk of comorbidities among HIV+ patients attending a New England ambulatory centre. Obes Sci Pract 2(2):123-127

Benjamin LA, Bryer A, Emsley HC, Khoo S, Solomon T, Connor MD (2012) HIV infection and stroke: current perspectives and future directions. Lancet Neurol 11(10):878-890

Blanco PJ, Müller LO, Spence JD (2017) Blood pressure gradients in cerebral arteries: a clue to pathogenesis of cerebral small vessel disease. Stroke Vasc Neurol 2(3):108-117

Boccara F, Cohen A (2016) HIV and heart disease: what cardiologists should know. Rev Esp Cardiol (Engl Ed) 69(12):1126-1130

Boccara F, Lang S, Meuleman C, Ederhy S, Mary-Krause M, Costagliola D et al (2013) HIV and coronary heart disease. J Am Coll Cardiol 61(5):511-523

Bonnet F, Amieva H, Marquant F, Bernard C, Bruyand M, Dauchy F-A et al (2013) Cognitive disorders in HIV-infected patients: are they HIV-related? AIDS 27(3):391-400

Borshchev YY, Uspensky YP, Galadgudza MM (2019) Pathogenetic pathways of cognitive dysfunction and dementia in metabolic syndrome. Life Sci 237:116932

Brew BJ (2016) Has HIV-associated neurocognitive disorders now transformed into vascular cognitive impairment? AIDS 30(15):2379-2380

Burkauskas J, Lang P, Bunevičius A, Neverauskas J, Bučiūtè-Jankauskienė M, Mickuvienė N (2018) Cognitive function in patients with coronary artery disease: a literature review. J Int Med Res 46(10):4019-4031

Calò LA, Caielli P, Maiolino G, Rossi G (2013) Arterial hypertension and cardiovascular risk in HIV-infected patients. J Cardiovasc Med Hagerstown 14(8):553-558

Calza L, Colangeli V, Magistrelli E, Rossi N, Rosselli Del Turco E, Bussini L et al (2017) Prevalence of metabolic syndrome in HIV-infected patients naive to antiretroviral therapy or receiving a first-line treatment. HIV Clin Trials 18(3):110-117

Canet G, Dias C, Gabelle A, Simonin Y, Gosselet F, Marchi N et al (2018) HIV neuroinfection and Alzheimer's disease: similarities and potential links? Front Cell Neurosci 12:307

Cannistraro RJ, Badi M, Eidelman BH, Dickson DW, Middlebrooks EH, Meschia JF (2019) CNS small vessel disease: a clinical review. Neurology 92(24):1146-1156

Carey CL, Woods SP, Gonzalez R, Conover E, Marcotte TD, Grant I et al (2004) Predictive validity of global deficit scores in detecting neuropsychological impairment in HIV infection. J Clin Exp Neuropsychol 26(3):307-319

Caruana G, Vidili G, Serra PA, Bagella P, Spanu A, Fiore V et al (2017) The burden of HIV-associated neurocognitive disorder (HAND) in post-HAART era: a multidisciplinary review of the literature. Eur Rev Med Pharmacol Sci 21(9):2290-2301

Cavalieri M, Ropele S, Petrovic K, Pluta-Fuerst A, Homayoon N, Enzinger C et al (2010) Metabolic syndrome, brain magnetic resonance imaging, and cognition. Diabetes Care 33(12):2489-2495

Chaganti JR, Heinecke A, Gates TM, Moffat KJ, Brew BJ (2017) Functional connectivity in virally suppressed patients with HIV-associated neurocognitive disorder: a resting-state analysis. Am J Neuroradiol 38(8):1623-1629

Charidimou A, Pantoni L, Love S (2016) The concept of sporadic cerebral small vessel disease: a road map on key definitions and current concepts. Int J Stroke 11(1):6-18

Chong JY, Sacco RL (2005) Epidemiology of stroke in young adults: race/ethnic differences. J Thromb Thrombolysis 20(2):77-83

Chow FC, Bacchetti P, Kim AS, Price RW, Hsue PY (2014a) Effect of CD4+ cell count and viral suppression on risk of ischemic stroke in HIV infection. AIDS 28(17):2573-2577

Chow FC, He W, Bacchetti P, Regan S, Feske SK, Meigs JB et al (2014b) Elevated rates of intracerebral hemorrhage in individuals from a US clinical care HIV cohort. Neurology 83 (19): 1705-1711

Chow FC, Price RW, Hsue PY, Kim AS (2017) Greater risk of stroke of undetermined etiology in a contemporary HIV-infected cohort compared with uninfected individuals. J Stroke Cerebrovasc Dis 26(5):1154-1160 
Chui HC, Gomez LR (2017) Vascular contributions to cognitive impairment in late life. Neurol Clin 35(2):295-323

Ciccarelli N, Grima P, Fabbiani M, Baldonero E, Borghetti A, Milanini B et al (2014) Baseline $\mathrm{CD} 4+\mathrm{T}$-cell count and cardiovascular risk factors predict the evolution of cognitive performance during 2 years follow-up in HIV-infected patients. Antivir Ther 20(4):433-440

Cohen RA, Seider TR, Navia B (2015) HIV effects on age-associated neurocognitive dysfunction: premature cognitive aging or neurodegenerative disease? Alzheimers Res Ther 7(1):37

Corral I, Quereda C, Moreno A, Pérez-Elías M-J, Dronda F, Casado J-L et al (2009) Cerebrovascular ischemic events in HIV-1-infected patients receiving highly active antiretroviral therapy: incidence and risk factors. Cerebrovasc Dis 27(6):559-563

Cosentino SA, Jefferson AL, Carey M, Price CC, Davis-Garrett K, Swenson R et al (2004) The clinical diagnosis of vascular dementia: a comparison among four classification systems and a proposal for a new paradigm. Clin Neuropsychol 18(1):6-21

Costa CRB, Melo ES, Antonini M, Jesus GJ, Pontes PS, Gir E et al (2019) Association between sociodemographic and behavioral factors with metabolic syndrome in people living with HIV. Rev Gaucha Enferm 40:e20180379

Costagliola D (2014) Demographics of HIV and aging. Curr Opin HIV AIDS 9(4):294-301

Cova I, Clerici F, Maggiore L, Pomati S, Cucumo V, Ghiretti R et al (2016) Body mass index predicts progression of mild cognitive impairment to dementia. Dement Geriatr Cogn Disord 41 (3-4):172-180

Creavin ST, Gallacher J, Bayer A, Fish M, Ebrahim S, Ben-Shlomo Y (2012) Metabolic syndrome, diabetes, poor cognition, and dementia in the Caerphilly prospective study. J Alzheimers Dis 28 (4):931-939

Crichton GE, Elias MF, Buckley JD, Murphy KJ, Bryan J, Frisardi V (2012) Metabolic syndrome, cognitive performance, and dementia. J Alzheimers Dis 30(Suppl 2):S77-S87

Cuadrado-Godia E, Dwivedi P, Sharma S, Ois Santiago A, Roquer Gonzalez J, Balcells M et al (2018) Cerebral small vessel disease: a review focusing on pathophysiology, biomarkers, and machine learning strategies. J Stroke 20(3):302-320

Cysique LA, Messinis L, Albert SM (2019) Could excess body weight be good for cognitive health in chronic HIV infection? Neurology 93(3):95-96

Czuriga-Kovács KR, Czuriga D, Csiba L (2016) Influence of hypertension, alone and in combination with other vascular risk factors on cognition. CNS Neurol Disord Drug Targets 15 (6):690-698

D’Ascenzo F, Quadri G, Cerrato E, Calcagno A, Omedè P, Grosso Marra W et al (2015) A metaanalysis investigating incidence and features of stroke in HIV-infected patients in the highly active antiretroviral therapy era. J Cardiovasc Med 16(12):839-843

Das AS, Regenhardt RW, Vernooij MW, Blacker D, Charidimou A, Viswanathan A (2019) Asymptomatic cerebral small vessel disease: insights from population-based studies. J Stroke 21(2):121-138

Daskalopoulou SS, Athyros VG, Kolovou GD, Anagnostopoulou KK, Mikhailidis DP (2006) Definitions of metabolic syndrome: where are we now? Curr Vasc Pharmacol 4(3):185-197

Davies J, Everall IP, Weich S, McLaughlin J, Scaravilli F, Lantos PL (1997) HIV-associated brain pathology in the United Kingdom: an epidemiological study. AIDS 11(9):1145-1150

Desai NK, Mullins ME (2014) An imaging approach to diffuse white matter changes. Radiol Clin North Am 52(2):263-278

Dey AK, Stamenova V, Bacopulos A, Jeyakumar N, Turner GR, Black SE et al (2019) Cognitive heterogeneity among community-dwelling older adults with cerebral small vessel disease. Neurobiol Aging 77:183-193

Du J, Xu Q (2019) Neuroimaging studies on cognitive impairment due to cerebral small vessel disease. Stroke Vasc Neurol 4(2):99-101

Dufouil C, Richert L, Thiébaut R, Bruyand M, Amieva H, Dauchy F-A et al (2015) Diabetes and cognitive decline in a French cohort of patients infected with HIV-1. Neurology 85 (12):1065-1073 
Dye L, Boyle NB, Champ C, Lawton C (2017) The relationship between obesity and cognitive health and decline. Proc Nutr Soc 76(04):443-454

Ellis R, Langford D, Masliah E (2007) HIV and antiretroviral therapy in the brain: neuronal injury and repair. Nat Rev Neurosci 8(1):33-44

Emmerzaal TL, Kiliaan AJ, Gustafson DR (2015) 2003-2013: a decade of body mass index, Alzheimer's disease, and dementia. J Alzheimers Dis 43(3):739-755

Ervin RB (2009) Prevalence of metabolic syndrome among adults 20 years of age and over, by sex, age, race and ethnicity, and body mass index: United States, 2003-2006. Natl Health Stat Rep $13: 1-7$

Everall IP, Hansen LA, Masliah E (2005) The shifting patterns of HIV encephalitis neuropathology. Neurotox Res 8(1-2):51-61

Everall I, Vaida F, Khanlou N, Lazzaretto D, Achim C, Letendre S et al (2009) Cliniconeuropathologic correlates of human immunodeficiency virus in the era of antiretroviral therapy. J Neurovirol 15(5-6):360-370

Fabbiani M, Ciccarelli N, Tana M, Farina S, Baldonero E, di Cristo V et al (2013) Cardiovascular risk factors and carotid intima-media thickness are associated with lower cognitive performance in HIV-infected patients: cardiovascular risk and cognition in HIV. HIV Med 14(3):136-144

Fazekas F, Chawluk JB, Alavi A, Hurtig HI, Zimmerman RA (1987) MR signal abnormalities at 1.5 $\mathrm{T}$ in Alzheimer's dementia and normal aging. Am J Roentgenol 149(2):351-356

Fleming J, Mathews WC, Rutstein RM, Aberg J, Somboonwit C, Cheever LW et al (2019) Low level viremia and virologic failure in persons with HIV infection treated with antiretroviral therapy. AIDS 33(13):2005-2012

Fogel GB, Lamers SL, Levine AJ, Valdes-Sueiras M, McGrath MS, Shapshak P et al (2015) Factors related to HIV-associated neurocognitive impairment differ with age. J Neurovirol 21(1):56-65

Foley J, Ettenhofer M, Wright MJ, Siddiqi I, Choi M, Thames AD et al (2010) Neurocognitive functioning in HIV-1 infection: effects of cerebrovascular risk factors and age. Clin Neuropsychol 24(2):265-285

Frazier DT, Seider T, Bettcher BM, Mack WJ, Jastrzab L, Chao L et al (2014) The role of carotid intima-media thickness in predicting longitudinal cognitive function in an older adult cohort. Cerebrovasc Dis 38(6):441-447

Gelman BB (2015) Neuropathology of HAND with suppressive antiretroviral therapy: encephalitis and neurodegeneration reconsidered. Curr HIV/AIDS Rep 12(2):272-279

Gisslén M, Price RW, Nilsson S (2011) The definition of HIV-associated neurocognitive disorders: are we overestimating the real prevalence? BMC Infect Dis 11:356

Godefroy O, Leclercq C, Bugnicourt J-M, Roussel M, Moroni C, Quaglino V et al (2013) Neuropsychological assessment and cerebral vascular disease: the new standards. Rev Neurol (Paris) 169(10):779-785

Gongvatana A, Cohen RA, Correia S, Devlin KN, Miles J, Kang H et al (2011) Clinical contributors to cerebral white matter integrity in HIV-infected individuals. J Neurovirol 17(5):477-486

Gorelick PB, Scuteri A, Black SE, Decarli C, Greenberg SM, Iadecola C et al (2011) Vascular contributions to cognitive impairment and dementia: a statement for healthcare professionals from the American Heart Association/American Stroke Association. Stroke 42(9):2672-2713

Gouw AA, Seewann A, van der Flier WM, Barkhof F, Rozemuller AM, Scheltens P et al (2011) Heterogeneity of small vessel disease: a systematic review of MRI and histopathology correlations. J Neurol Neurosurg Psychiatry 82(2):126-135

Greenberg SM (2006) Small vessels, big problems. N Engl J Med 354(14):1451-1453

Grundy SM (2008) Metabolic syndrome pandemic. Arterioscler Thromb Vasc Biol 28(4):629-636

Guaraldi G, Zona S, Alexopoulos N, Orlando G, Carli F, Ligabue G et al (2009) Coronary aging in HIV-infected patients. Clin Infect Dis 49(11):1756-1762

Gustafson DR, Mielke MM, Tien PC, Valcour V, Cohen M, Anastos K et al (2013) Anthropometric measures and cognition in middle-aged HIV-infected and uninfected women. The Women's Interagency HIV Study. J Neurovirol 19(6):574-585 
Gutierrez J, Albuquerque ALA, Falzon L (2017) HIV infection as vascular risk: a systematic review of the literature and meta-analysis. PLoS One 12(5):e0176686

Haddow LJ, Pierce KJ, Daskalopoulou M, Lampe F, Rodger AJ (2015) Neurocognitive change observed in the charter HIV cohort could be due to chance, and may be a cause as well as a consequence of detectable viremia. Clin Infect Dis 60(9):1441-1442

Hanna DB, Guo M, Bůžková P, Miller TL, Post WS, Stein JH et al (2016) HIV infection and carotid artery intima-media thickness: pooled analyses across 5 cohorts of the NHLBI HIV-CVD collaborative. Clin Infect Dis 63(2):249-256

Hart RG, Catanese L, Perera KS, Ntaios G, Connolly SJ (2017) Embolic stroke of undetermined source: a systematic review and clinical update. Stroke 48(4):867-872

Hassenstab JJ, Sweat V, Bruehl H, Convit A (2010) Metabolic syndrome is associated with learning and recall impairment in middle age. Dement Geriatr Cogn Disord 29(4):356-362

Hatleberg CI, Lundgren JD, Ryom L (2017) Are we successfully managing cardiovascular disease in people living with HIV? Curr Opin HIV AIDS 12(6):594-603

Hill A, Waters L, Pozniak A (2019) Are new antiretroviral treatments increasing the risks of clinical obesity? J Virus Erad 5(1):41-43

Hsu JC, Li Y, Marcus GM, Hsue PY, Scherzer R, Grunfeld C et al (2013) Atrial fibrillation and atrial flutter in human immunodeficiency virus-infected persons. J Am Coll Cardiol 61 (22):2288-2295

Januel E, Godin O, Moulignier A, Lescure F-X, Savatovsky J, Lamirel C et al (2019) Brief report: impact of ART classes on the increasing risk of cerebral small-vessel disease in middle-aged, well-controlled, cART-treated, HIV-infected individuals. J Acquir Immune Defic Syndr 81 (5):547-551

Jellinger KA (2013) Pathology and pathogenesis of vascular cognitive impairment - a critical update. Front Aging Neurosci 5:17

Jensen BK, Roth LM, Grinspan JB, Jordan-Sciutto KL (2019) White matter loss and oligodendrocyte dysfunction in HIV: a consequence of the infection, the antiretroviral therapy or both? Brain Res 1724:146397

Jeong SJ, Kim HW, Ku NS, Han SH, Kim CO, Choi JY et al (2013) Clinical factors associated with carotid plaque and intima-medial thickness in HIV-infected patients. Yonsei Med J 54 (4):990-998

Jimenez-Conde J, Biffi A, Rahman R, Kanakis A, Butler C, Sonni S et al (2010) Hyperlipidemia and reduced white matter hyperintensity volume in patients with ischemic stroke. Stroke 41 (3):437-442

Jokinen H, Kalska H, Ylikoski R, Madureira S, Verdelho A, van der Flier WM et al (2009) Longitudinal cognitive decline in subcortical ischemic vascular disease - The LADIS Study. Cerebrovasc Dis 27(4):384-391

Jokinen H, Melkas S, Madureira S, Verdelho A, Ferro JM, Fazekas F et al (2016) Cognitive reserve moderates long-term cognitive and functional outcome in cerebral small vessel disease. J Neurol Neurosurg Psychiatry 87(12):1296-1302

Kaiser D, Weise G, Möller K, Scheibe J, Pösel C, Baasch S et al (2014) Spontaneous white matter damage, cognitive decline and neuroinflammation in middle-aged hypertensive rats: an animal model of early-stage cerebral small vessel disease. Acta Neuropathol Commun 2:169

Kanekar S, Devgun P (2014) A pattern approach to focal white matter hyperintensities on magnetic resonance imaging. Radiol Clin North Am 52(2):241-261

Kerchberger AM, Sheth AN, Angert CD, Mehta CC, Summers NA, Ofotokun I et al (2019) Weight gain associated with integrase stand transfer inhibitor use in women. Clin Infect Dis Off Publ Infect Dis Soc Am. https://doi.org/10.1093/cid/ciz853

Kerwin DR, Gaussoin SA, Chlebowski RT, Kuller LH, Vitolins M, Coker LH et al (2011) Interaction between body mass index and central adiposity and risk of incident cognitive impairment and dementia: results from the Women's Health Initiative Memory Study. J Am Geriatr Soc 59(1):107-112 
Khaledi M, Haghighatdoost F, Feizi A, Aminorroaya A (2019) The prevalence of comorbid depression in patients with type 2 diabetes: an updated systematic review and meta-analysis on huge number of observational studies. Acta Diabetol 56(6):631-650

Khan A, Kalaria RN, Corbett A, Ballard C (2016) Update on vascular dementia. J Geriatr Psychiatry Neurol 29(5):281-301

Khuder SS, Chen S, Letendre S, Marcotte T, Grant I, Franklin D et al (2019) Impaired insulin sensitivity is associated with worsening cognition in HIV-infected patients. Neurology 92(12): e1344-e1353

Kiliaan AJ, Arnoldussen IAC, Gustafson DR (2014) Adipokines: a link between obesity and dementia? Lancet Neurol 13(9):913-923

Kivipelto M, Ngandu T, Fratiglioni L, Viitanen M, Kareholt I, Winblad B et al (2005) Obesity and vascular risk factors at midlife and the risk of dementia and Alzheimer disease. Arch Neurol 62 (10):1556-1560

Klein DB, Leyden WA, Xu L, Chao CR, Horberg MA, Towner WJ et al (2015) Declining relative risk for myocardial infarction among HIV-positive compared with HIV-negative individuals with access to care. Clin Infect Dis 60(8):1278-1280

Kochunov P, Thompson PM, Lancaster JL, Bartzokis G, Smith S, Coyle T et al (2007) Relationship between white matter fractional anisotropy and other indices of cerebral health in normal aging: tract-based spatial statistics study of aging. Neuroimage 35(2):478-487

Kugathasan R, Collier DA, Haddow LJ, El Bouzidi K, Edwards SG, Cartledge JD et al (2017) Diffuse white matter signal abnormalities on magnetic resonance imaging are associated with human immunodeficiency virus type 1 viral escape in the central nervous system among patients with neurological symptoms. Clin Infect Dis 64(8):1059-1065

Lagathu C, Béréziat V, Gorwood J, Fellahi S, Bastard J-P, Vigouroux C et al (2019) Metabolic complications affecting adipose tissue, lipid and glucose metabolism associated with HIV antiretroviral treatment. Expert Opin Drug Saf 18(9):829-840

Lake JE, Vo QT, Jacobson LP, Sacktor N, Miller EN, Post WS et al (2015) Adiponectin and interleukin-6, but not adipose tissue, are associated with worse neurocognitive function in HIV-infected men. Antivir Ther 20(2):235-244

Lang S, Mary-Krause M, Simon A, Partisani M, Gilquin J, Cotte L et al (2012) HIV replication and immune status are independent predictors of the risk of myocardial infarction in HIV-infected individuals. Clin Infect Dis 55(4):600-607

Lang S, Boccara F, Mary-Krause M, Cohen A (2015) Epidemiology of coronary heart disease in HIV-infected versus uninfected individuals in developed countries. Arch Cardiovasc Dis 108 (3):206-215

Langford TD, Letendre SL, Marcotte TD, Ellis RJ, McCutchan JA, Grant I et al (2002) Severe, demyelinating leukoencephalopathy in AIDS patients on antiretroviral therapy. AIDS 16 (7):1019-1029

Lennon MJ, Makkar SR, Crawford JD, Sachdev PS (2019) Midlife hypertension and Alzheimer's disease: a systematic review and meta-analysis. J Alzheimers Dis 71(1):307-316

Lentz MR, Peterson KL, Ibrahim WG, Lee DE, Sarlls J, Lizak MJ et al (2014) Diffusion tensor and volumetric magnetic resonance measures as biomarkers of brain damage in a small animal model of HIV. PLoS One 9(8):e105752

Lescure F-X, Moulignier A, Savatovsky J, Amiel C, Carcelain G, Molina J-M et al (2013) CD8 encephalitis in HIV-infected patients receiving cART: a treatable entity. Clin Infect Dis 57 (1):101-108

Li Q, Yang Y, Reis C, Tao T, Li W, Li X et al (2018) Cerebral small vessel disease. Cell Transplant 27(12):1711-1722

Lin Q, Huang W-Q, Ma Q-L, Lu C-X, Tong S-J, Ye J-H et al (2017) Incidence and risk factors of leukoaraiosis from 4683 hospitalized patients: a cross-sectional study. Medicine (Baltimore) 96 (39):e7682

Lin H-L, Muo C-H, Lin C-Y, Chen H-J, Chen P-C (2019) Incidence of stroke in patients with HIV infection: a population-based study in Taiwan. Plos One 14(5):e0217147 
Lo Coco D, Lopez G, Corrao S (2016) Cognitive impairment and stroke in elderly patients. Vasc Health Risk Manag 12:105-116

Low A, Mak E, Rowe JB, Markus HS, O’Brien JT (2019) Inflammation and cerebral small vessel disease: a systematic review. Ageing Res Rev 53:100916

Lv Y-B, Yin ZX, Chei C-L, Brasher MS, Zhang J, Kraus VB et al (2016) Serum cholesterol levels within the high normal range are associated with better cognitive performance among Chinese elderly. J Nutr Health Aging 20(3):280-287

Ma C, Yin Z, Zhu P, Luo J, Shi X, Gao X (2017) Blood cholesterol in late-life and cognitive decline: a longitudinal study of the Chinese elderly. Mol Neurodegener 12(1):24

Madhavan M, Graff-Radford J, Piccini JP, Gersh BJ (2018) Cognitive dysfunction in atrial fibrillation. Nat Rev Cardiol 15(12):744-756

Makinson A, Dubois J, Eymard-Duvernay S, Leclercq P, Zaegel-Faucher O, Bernard L et al (2019) Increased prevalence of neurocognitive impairment in aging people living with human immunodeficiency virus: the ANRS EP58 HAND 55-70 study. Clin Infect Dis. https://doi.org/10. 1093/cid/ciz670

Marcus JL, Leyden WA, Chao CR, Chow FC, Horberg MA, Hurley LB et al (2014) HIV infection and incidence of ischemic stroke. AIDS 28(13):1911-1919

Marquine MJ, Heaton A, Johnson N, Rivera-Mindt M, Cherner M, Bloss C et al (2018) Differences in neurocognitive impairment among HIV-infected Latinos in the United States. J Int Neuropsychol Soc 24(02):163-175

McAleese KE, Alafuzoff I, Charidimou A, de Reuck J, Grinberg LT, Hainsworth AH et al (2016) Post-mortem assessment in vascular dementia: advances and aspirations. BMC Med 14(1):129

McCutchan JA, Marquie-Beck JA, Fitzsimons CA, Letendre SL, Ellis RJ, Heaton RK et al (2012) Role of obesity, metabolic variables, and diabetes in HIV-associated neurocognitive disorder. Neurology 78(7):485-492

McDonnell J, Haddow L, Daskalopoulou M, Lampe F, Speakman A, Gilson R et al (2014) Minimal cognitive impairment in UK HIV-positive men who have sex with men: effect of case definitions and comparison with the general population and HIV-negative men. J Acquir Immune Defic Syndr 67(2):120-127

McNicholas T, Tobin K, Carey D, O'Callaghan S, Kenny RA (2018) Is baseline orthostatic hypotension associated with a decline in global cognitive performance at 4-year follow-up? Data from TILDA (The Irish Longitudinal Study on Ageing). J Am Heart Assoc 7(19):e008976

Mellendijk L, Wiesmann M, Kiliaan A (2015) Impact of nutrition on cerebral circulation and cognition in the metabolic syndrome. Nutrients 7(11):9416-9439

Meyer A-CL, Boscardin WJ, Kwasa JK, Price RW (2013) Is it time to rethink how neuropsychological tests are used to diagnose mild forms of HIV-associated neurocognitive disorders? Impact of false-positive rates on prevalence and power. Neuroepidemiology 41(3-4):208-216

Morgello S, Murray J, van der Elst S, Byrd D (2014) HCV, but not HIV, is a risk factor for cerebral small vessel disease. Neurol Neuroimmunol Neuroinflamm 1(3):e27

Moritani T, Capizzano A, Kirby P, Policeni B (2014) Viral infections and white matter lesions. Radiol Clin North Am 52(2):355-382

Morley JE (2014) Cognition and nutrition. Curr Opin Clin Nutr Metab Care 17(1):1-4

Moulignier A, Lamirel C, Mazighi M (2015) Stroke and HIV infection. Sang Thromb Vaiss 2:84-95

Moulignier A, Savatovsky J, Assoumou L, Lescure F-X, Lamirel C, Godin O et al (2018) Silent cerebral small-vessel disease is twice as prevalent in middle-aged individuals with wellcontrolled, combination antiretroviral therapy-treated human immunodeficiency virus (HIV) than in HIV-uninfected individuals. Clin Infect Dis 66(11):1762-1769

Mukerji SS, Locascio JJ, Misra V, Lorenz DR, Holman A, Dutta A et al (2016) Lipid profiles and apoe4 allele impact midlife cognitive decline in HIV-Infected men on antiretroviral therapy. Clin Infect Dis 63(8):1130-1139

Muller M, Tang M-X, Schupf N, Manly JJ, Mayeux R, Luchsinger JA (2007) Metabolic syndrome and dementia risk in a multiethnic elderly cohort. Dement Geriatr Cogn Disord 24(3):185-192 
Nakamoto BK, Jahanshad N, McMurtray A, Kallianpur KJ, Chow DC, Valcour VG et al (2012) Cerebrovascular risk factors and brain microstructural abnormalities on diffusion tensor images in HIV-infected individuals. J Neurovirol 18(4):303-312

Navia BA, Cho ES, Petito CK, Price RW (1986) The AIDS dementia complex: II. Neuropathology. Ann Neurol 19(6):525-535

Nightingale S, Winston A, Letendre S, Michael BD, McArthur JC, Khoo S et al (2014) Controversies in HIV-associated neurocognitive disorders. Lancet Neurol 13(11):1139-1151

Nir TM, Jahanshad N, Busovaca E, Wendelken L, Nicolas K, Thompson PM et al (2014) Mapping white matter integrity in elderly people with HIV. Hum Brain Mapp 35(3):975-992

Noble JM, Manly JJ, Schupf N, Tang M-X, Luchsinger JA (2012) Type 2 diabetes and ethnic disparities in cognitive impairment. Ethn Dis 22(1):38-44

Nobre N, Pereira M, Roine RP, Sutinen J, Sintonen H (2018) HIV-related self-stigma and healthrelated quality of life of people living with HIV in Finland. J Assoc Nurses AIDS Care 29 (2):254-265

Noubissi EC, Katte J-C, Sobngwi E (2018) Diabetes and HIV. Curr Diab Rep 18(11):125

O'Callaghan S, Kenny RA (2016) Neurocardiovascular instability and cognition. Yale J Biol Med 89(11):59-71

O'Connor EE, Jaillard A, Renard F, Zeffiro TA (2017) Reliability of white matter microstructural changes in HIV infection: meta-analysis and confirmation. Am J Neuroradiol 38(8):1510-1519

Okafor CN, Kelso NE, Bryant V, Burrell LE, Míguez MJ, Gongvatana A et al (2017) Body mass index, inflammatory biomarkers and neurocognitive impairment in HIV-infected persons. Psychol Health Med 22(3):289-302

On Behalf of the POPPY Study Group, de Francesco D, Underwood J, Post FA, Vera JH, Williams I et al (2016) Defining cognitive impairment in people-living-with-HIV: the POPPY study. BMC Infect Dis 16(1):617

Ott A, Breteler M, de Bruyne M, van Harskamp F, Grobbee D, Hofman A (1997) Atrial fibrillation and dementia in a population-based study. The Rotterdam Study. Stroke 28(2):316-321

Ovbiagele B, Nath A (2011) Increasing incidence of ischemic stroke in patients with HIV infection. Neurology 76(5):444-450

Pal S, Ellis V (2010) The chronic effects of whey proteins on blood pressure, vascular function, and inflammatory markers in overweight individuals. Obesity 18(7):1354-1359

Palta P, Snitz B, Carlson MC (2016) Neuropsychologic assessment. Handb Clin Neurol 138:107-119

Pantoni L (2010) Cerebral small vessel disease: from pathogenesis and clinical characteristics to therapeutic challenges. Lancet Neurol 9(7):689-701

Pantoni L, Fierini F, Poggesi A, LADIS Study Group (2015) Impact of cerebral white matter changes on functionality in older adults: an overview of the LADIS Study results and future directions: LADIS study. Geriatr Gerontol Int 15:10-16

Paradise MB, Sachdev PS (2019) Vascular cognitive disorder. Semin Neurol 39(2):241-250

Pastori D, Mezzaroma I, Pignatelli P, Violi F, Lip GYH (2019) Atrial fibrillation and human immunodeficiency virus type-1 infection: a systematic review. Implications for anticoagulant and antiarrhythmic therapy. Br J Clin Pharmacol 85(3):508-515

Pourcher G, Costagliola D, Martinez V (2015) Obesity in HIV-infected patients in France: prevalence and surgical treatment options. J Visc Surg 152(1):33-37

Rasmussen LD, Engsig FN, Christensen H, Gerstoft J, Kronborg G, Pedersen C et al (2011) Risk of cerebrovascular events in persons with and without HIV: a Danish nationwide population-based cohort study. AIDS 25(13):1637-1646

Reaven GM (1988) Banting lecture 1988. Role of insulin resistance in human disease. Diabetes 37 (12):1595-1607

Rubin LH, Gustafson D, Hawkins KL, Zhang L, Jacobson LP, Becker JT et al (2019) Midlife adiposity predicts cognitive decline in the prospective Multicenter AIDS Cohort Study. Neurology 93(3):e261-e271 
Sachdev P, Kalaria R, O'Brien J, Skoog I, Alladi S, Black SE et al (2014) Diagnostic criteria for vascular cognitive disorders: a VASCOG statement. Alzheimer Dis Assoc Disord 28 (3):206-218

Sacktor N, Skolasky RL, Seaberg E, Munro C, Becker JT, Martin E et al (2016) Prevalence of HIV-associated neurocognitive disorders in the Multicenter AIDS Cohort Study. Neurology 86 (4):334-340

Saloner R, Cysique LA (2017) HIV-associated neurocognitive disorders: a global perspective. J Int Neuropsychol Soc 23(9-10):860-869

Sanders JM, Steverson AB, Pawlowski AE, Schneider D, Achenbach CJ, Lloyd-Jones DM et al (2018) Atrial arrhythmia prevalence and characteristics for human immunodeficiency virusinfected persons and matched uninfected controls. Plos One 13(3):e0194754

Sanford R, Strain J, Dadar M, Maranzano J, Bonnet A, Mayo NE et al (2019) HIV infection and cerebral small vessel disease are independently associated with brain atrophy and cognitive impairment. AIDS 33(7):1197-1205

Sarbu N, Shih RY, Jones RV, Horkayne-Szakaly I, Oleaga L, Smirniotopoulos JG (2016) White matter diseases with radiologic-pathologic correlation. Radiogr Rev 36(5):1426-1447

Satizabal CL, Beiser AS, Chouraki V, Chêne G, Dufouil C, Seshadri S (2016) Incidence of dementia over three decades in the Framingham Heart Study. N Engl J Med 374(6):523-532

Sattler FR, He J, Letendre S, Wilson C, Sanders C, Heaton R et al (2015) Abdominal obesity contributes to neurocognitive impairment in HIV-infected patients with increased inflammation and immune activation. J Acquir Immune Defic Syndr 68(3):281-288

Schouten J, Su T, Wit FW, Kootstra NA, Caan MWA, Geurtsen GJ et al (2016) Determinants of reduced cognitive performance in HIV-1-infected middle-aged men on combination antiretroviral therapy. AIDS 30(7):1027-1038

Schreiber S, Wilisch-Neumann A, Schreiber F, Assmann A, Scheumann V, Perosa V et al (2019) Invited review: the spectrum of age-related small vessel diseases: potential overlap and interactions of amyloid and nonamyloid vasculopathies. Neuropathol Appl Neurobiol. https://doi.org/10.1111/nan.12576

Schuur M, Henneman P, van Swieten JC, Zillikens MC, de Koning I, Janssens ACJW et al (2010) Insulin-resistance and metabolic syndrome are related to executive function in women in a large family-based study. Eur J Epidemiol 25(8):561-568

Sepehri Shamloo A, Dagres N, Müssigbrodt A, Stauber A, Kircher S, Richter S et al (2019) Atrial fibrillation and cognitive impairment: new insights and future directions. Heart Lung Circ. https://doi.org/10.1016/j.hlc.2019.05.185

Shi Y, Wardlaw JM (2016) Update on cerebral small vessel disease: a dynamic whole-brain disease. Stroke Vasc Neurol 1(3):83-92

Shoamanesh A, Preis SR, Beiser AS, Vasan RS, Benjamin EJ, Kase CS et al (2015) Inflammatory biomarkers, cerebral microbleeds, and small vessel disease Framingham Heart Study. Neurology 84(8):825-832

Sico JJ, Chang C-CH, So-Armah K, Justice AC, Hylek E, Skanderson M et al (2015) HIV status and the risk of ischemic stroke among men. Neurology 84(19):1933-1940

Simioni S, Cavassini M, Annoni J-M, Rimbault Abraham A, Bourquin I, Schiffer V et al (2010) Cognitive dysfunction in HIV patients despite long-standing suppression of viremia. AIDS 24 (9): $1243-1250$

Skrobot OA, Black SE, Chen C, DeCarli C, Erkinjuntti T, Ford GA et al (2018) Progress toward standardized diagnosis of vascular cognitive impairment: guidelines from the Vascular Impairment of Cognition Classification Consensus Study. Alzheimers Dement J Alzheimers Assoc 14 (3):280-292

Sloan MA, Kittner SJ, Feeser BR, Gardner J, Epstein A, Wozniak MA et al (1998) Illicit drugassociated ischemic stroke in the Baltimore-Washington Young Stroke Study. Neurology 50 (6):1688-1693 
Soontornniyomkij V, Umlauf A, Chung SA, Cochran ML, Soontornniyomkij B, Gouaux B et al (2014) HIV protease inhibitor exposure predicts cerebral small vessel disease. AIDS 28 (9):1297-1306

Su T, Wit FWNM, Caan MWA, Schouten J, Prins M, Geurtsen GJ et al (2016) White matter hyperintensities in relation to cognition in HIV-infected men with sustained suppressed viral load on combination antiretroviral therapy. AIDS 30(15):2329-2339

Sundbøll J (2018) Depression, stroke, and dementia in patients with myocardial infarction. Dan Med J 65(4):B5423

The SPRINT MIND, Investigators for the SPRINT Research Group, Williamson JD, Pajewski NM, Auchus AP, Bryan RN, Chelune G et al (2019) Effect of intensive vs standard blood pressure control on probable dementia: a randomized clinical trial. JAMA 321(6):553-561

Torti C, Focà E, Cesana BM, Lescure FX (2011) Asymptomatic neurocognitive disorders in patients infected by HIV: fact or fiction? BMC Med 9:138

Trentalange A, Prochet A, Imperiale D, Cusato J, Tettoni M, Nunnari G et al (2018) Cerebral white matter hyperintensities in HIV-positive patients. Brain Imaging Behav. https://doi.org/10.1007/ s11682-018-9966-1

Tsivgoulis G, Alexandrov AV, Wadley VG, Unverzagt FW, Go RCP, Moy CS et al (2009) Association of higher diastolic blood pressure levels with cognitive impairment. Neurology 73(8):589-592

Underwood J, Cole JH, Caan M, de Francesco D, Leech R, van Zoest RA et al (2017) Gray and white matter abnormalities in treated human immunodeficiency virus disease and their relationship to cognitive function. Clin Infect Dis 65(3):422-432

Underwood J, de Francesco D, Leech R, Sabin CA, Winston A, Pharmacokinetic and Clinical Observations in PeoPle Over fiftY (POPPY) Study (2018) Medicalising normality? Using a simulated dataset to assess the performance of different diagnostic criteria of HIV-associated cognitive impairment. PLoS One 13(4):e0194760

Underwood J, de Francesco D, Cole JH, Caan MW, van Zoest RA, Schmand BA, et al. Validation of a novel multivariate method of defining HIV-associated cognitive impairment. In: Open forum infectious diseases. Oxford University Press, Oxford; 2019. 6(6):ofz198.

Utrecht Vascular Cognitive Impairment Study Group, de Bresser J, Kuijf HJ, Zaanen K, Viergever MA, Hendrikse J et al (2018) White matter hyperintensity shape and location feature analysis on brain MRI; proof of principle study in patients with diabetes. Sci Rep 8(1):1893

Valcour VG, Shikuma CM, Shiramizu BT, Williams AE, Watters MR, Poff PW et al (2005) Diabetes, insulin resistance, and dementia among HIV-1-infected patients. J Acquir Immune Defic Syndr 38(1):31-36

Valcour VG, Sacktor NC, Paul RH, Watters MR, Selnes OA, Shiramizu BT et al (2006) Insulin resistance is associated with cognition among HIV-1-infected patients: the Hawaii Aging with HIV cohort. J Acquir Immune Defic Syndr 43(4):405-410

van den Berg E, Biessels GJ, de Craen AJ, Gussekloo J, Westendorp RGJ (2007) The metabolic syndrome is associated with decelerated cognitive decline in the oldest old. Neurology 69 (10):979-985

van den Munckhof ICL, Jones H, Hopman MTE, de Graaf J, Nyakayiru J, van Dijk B et al (2018) Relation between age and carotid artery intima-medial thickness: a systematic review. Clin Cardiol 41(5):698-704

van der Flier WM, Skoog I, Schneider JA, Pantoni L, Mok V, Chen CLH et al (2018) Vascular cognitive impairment. Nat Rev Dis Primers 4:18003

van Zoest RA, Underwood J, de Francesco D, Sabin CA, Cole JH, Wit FW et al (2018) Structural brain abnormalities in successfully treated HIV infection: associations with disease and cerebrospinal fluid biomarkers. J Infect Dis 217(1):69-81

Vinikoor MJ, Napravnik S, Floris-Moore M, Wilson S, Huang DY, Eron JJ (2013) Incidence and clinical features of cerebrovascular disease among HIV-infected adults in the Southeastern United States. AIDS Res Hum Retroviruses 29(7):1068-1074 
Vivithanaporn P, Heo G, Gamble J, Krentz HB, Hoke A, Gill MJ et al (2010) Neurologic disease burden in treated HIV/AIDS predicts survival: a population-based study. Neurology 75 (13): $1150-1158$

Vizzardi E, Gelsomino S, D'Aloia A, Lorusso R (2013) Aortic atheromas and stroke: review of literature. J Invest Med 61(6):956-966

Wang T, Yi R, Green LA, Chelvanambi S, Seimetz M, Clauss M (2015) Increased cardiovascular disease risk in the HIV-positive population on ART: potential role of HIV-Nef and Tat. Cardiovasc Pathol 24(5):279-282

Wardlaw JM, Smith C, Dichgans M (2013a) Mechanisms of sporadic cerebral small vessel disease: insights from neuroimaging. Lancet Neurol 12(5):483-497

Wardlaw JM, Smith EE, Biessels GJ, Cordonnier C, Fazekas F, Frayne R et al (2013b) Neuroimaging standards for research into small vessel disease and its contribution to ageing and neurodegeneration. Lancet Neurol 12(8):822-838

Wardlaw JM, Valdés Hernández MC, Muñoz-Maniega S (2015) What are white matter hyperintensities made of? Relevance to vascular cognitive impairment. J Am Heart Assoc 4 (6):001140

Watson C, Busovaca E, Foley JM, Allen IE, Schwarz CG, Jahanshad N et al (2017) White matter hyperintensities correlate to cognition and fiber tract integrity in older adults with HIV. J Neurovirol 23(3):422-429

Wiederkehr S, Simard M, Fortin C, van Reekum R (2008a) Comparability of the clinical diagnostic criteria for vascular dementia: a critical review. Part I. J Neuropsychiatry Clin Neurosci 20 (2):150-161

Wiederkehr S, Simard M, Fortin C, van Reekum R (2008b) Validity of the clinical diagnostic criteria for vascular dementia: a critical review. Part II. J Neuropsychiatry Clin Neurosci 20 (2):162-177

Wijndaele K, Duvigneaud N, Matton L, Duquet W, Delecluse C, Thomis M et al (2009) Sedentary behaviour, physical activity and a continuous metabolic syndrome risk score in adults. Eur J Clin Nutr 63(3):421-429

Wright EJ, Grund B, Robertson K, Brew BJ, Roediger M, Bain MP et al (2010) Cardiovascular risk factors associated with lower baseline cognitive performance in HIV-positive persons. Neurology 75(10):864-873

Wright EJ, Grund B, Cysique LA, Robertson KR, Brew BJ, Collins G et al (2015) Factors associated with neurocognitive test performance at baseline: a substudy of the INSIGHT Strategic Timing of AntiRetroviral Treatment (START) trial. HIV Med 16(Suppl 1):97-108

Wu M, Fatukasi O, Yang S, Alger J, Barker PB, Hetherington H et al (2018) HIV disease and diabetes interact to affect brain white matter hyperintensities and cognition. AIDS 32 (13): 1803-1810

Yaffe K, Barrett-Connor E, Lin F, Grady D (2002) Serum lipoprotein levels, statin use, and cognitive function in older women. Arch Neurol 59(3):378-384

Yaffe K, Kanaya A, Lindquist K, Simonsick EM, Harris T, Shorr RI et al (2004) The metabolic syndrome, inflammation, and risk of cognitive decline. JAMA 292(18):2237-2242

Yaffe K, Haan M, Blackwell T, Cherkasova E, Whitmer RA, West N (2007) Metabolic syndrome and cognitive decline in elderly Latinos: findings from the Sacramento Area Latino Study of Aging study. J Am Geriatr Soc 55(5):758-762

Yang M, Williamson J (2019) Blood pressure and statin effects on cognition: a review. Curr Hypertens Rep 21(9):70

Yang J, Jacobson LP, Becker JT, Levine A, Martin EM, Munro CA et al (2018) Impact of glycemic status on longitudinal cognitive performance in men with and without HIV infection. AIDS 32 (13): $1849-1860$

Yates KF, Sweat V, Yau PL, Turchiano MM, Convit A (2012) Impact of metabolic syndrome on cognition and brain: a selected review of the literature. Arterioscler Thromb Vasc Biol 32 (9):2060-2067 
Yin Z-X, Shi X-M, Kraus VB, Fitzgerald SM, Qian H-Z, Xu J-W et al (2012) High normal plasma triglycerides are associated with preserved cognitive function in Chinese oldest-old. Age Ageing 41(5):600-606

Yin Z-G, Cui M, Zhou S-M, Yu M-M, Li R, Zhou H-D (2014) Association between metabolic syndrome and white matter lesions in middle-aged and elderly patients. Eur J Neurol 21 (7):1032-1039

Yu B, Pasipanodya E, Montoya JL, Moore RC, Gianella S, McCutchan A et al (2019) Metabolic syndrome and neurocognitive deficits in HIV infection. J Acquir Immune Defic Syndr 81 (1):95-101

Zhong W, Cruickshanks KJ, Schubert CR, Acher CW, Carlsson CM, Klein BEK et al (2012) Carotid atherosclerosis and 10-year changes in cognitive function. Atherosclerosis 224 (2):506-510

Zhuang L, Sachdev PS, Trollor JN, Kochan NA, Reppermund S, Brodaty H et al (2012) Microstructural white matter changes in cognitively normal individuals at risk of amnestic MCI. Neurology 79(8):748-754

Open Access This chapter is licensed under the terms of the Creative Commons Attribution 4.0 International License (http://creativecommons.org/licenses/by/4.0/), which permits use, sharing, adaptation, distribution and reproduction in any medium or format, as long as you give appropriate credit to the original author(s) and the source, provide a link to the Creative Commons licence and indicate if changes were made.

The images or other third party material in this chapter are included in the chapter's Creative Commons licence, unless indicated otherwise in a credit line to the material. If material is not included in the chapter's Creative Commons licence and your intended use is not permitted by statutory regulation or exceeds the permitted use, you will need to obtain permission directly from the copyright holder. 